IFN Working Paper No. 903, 2012

\title{
Network Competition with Income Effects
}

\section{Thomas P. Tangerås}




\title{
Network competition with income effects*
}

\author{
Thomas P. Tangerås \\ Research Institute of Industrial Economics (IFN) \\ P.O. Box 55665, SE-102 15 Stockholm, Sweden \\ E-mail: thomas.tangeras@ifn.se \\ Homepage: www.ifn.se/thomast
}

January 7, 2014

\begin{abstract}
I generalize the workhorse model of network competition to include income effects in demand. Empirical work has shown income effects to be positive and statistically significant. Income effects deliver theoretical results consistent with regulatory concern about excessive termination rates: Unregulated network operators competing in non-discriminatory retail contracts negotiate termination rates above cost for any positive income effect. This also holds when operators discriminate between on-net and off-net calls if networks are differentiated. Operators profit from increasing termination rates above cost under second-degree price discrimination if a sufficient share of consumers prefer on-net/off-net contracts and their subscription demand is relatively inelastic.

Keywords: Income effects, network competition, profit neutrality, second-degree price discrimination, termination-based discrimination.
\end{abstract}

JEL classification: L51, L96

*Many thanks to Mark Armstrong, Sven-Olof Fridolfsson, Pär Holmberg, Johannes Mauritzen, Lars Persson, Yossi Spiegel, Johan Stennek, Joacim Tåg, seminar/conference participants at IFN, Aalto University and Telecom ParisTech for valuable comments, Max Brimberg for research assistance, Christina Lönnblad and Dina Neiman for proof-reading the manuscript. Financial support from Almega and the NET Institute (www.netinst.org) is gratefully acknowledged. 


\section{Introduction}

The workhorse model of network competition generates a number of puzzling predictions concerning the termination rates network operators charge for connecting calls from one another and regarding call prices. First, theory predicts network profit to be independent of the reciprocal termination rate when operators compete in two-part call tariffs and charge non-discriminatory call prices (Laffont, Rey and Tirole, 1998a). In reality, profit margins tend to fall whenever network operators are forced by regulators to lower their termination rates (Genakos and Valletti, 2011). This discrepancy between predicted and observed effects on profit constitutes a profit neutrality puzzle. ${ }^{1}$

Profit is no longer independent of the termination rate when network operators engage in price discrimination between network internal (on-net) and external (off-net) calls; see Laffont, Rey and Tirole (1998b). Yet, termination-based discrimination addresses the profit neutrality puzzle only to introduce another. Operators now have an incentive to agree on termination rates below cost (Gans and King, 2001). As off-net calls then have a lower perceived marginal cost than on-net calls, the workhorse model predicts off-net call prices below on-net call prices. In reality, off-net calls are nearly always more expensive than on-net calls under price discrimination. This discrepancy between predicted and observed call prices constitutes an off-net puzzle.

This paper shows that income effects in demand can solve both the profit neutrality puzzle and the off-net puzzle. I introduce income effects by assuming a decreasing marginal utility of income, and consider network competition under the assumption of non-discriminatory contracts, termination-based discrimination, and when consumers are heterogenous so that networks engage in second-degree price discrimination. I establish conditions under which even weak income effects are enough to induce unregulated network operators to raise termination rates above cost.

Extending the model to include income effects is empirically relevant. In a study of residential telephony in France, Aldebert et al. (2004) find that consumers in higher income classes make significantly more local and national calls than consumers in lower income classes. ${ }^{2}$ For example, the estimated income elasticity of demand for local calls was approximately 20. With a monthly subscription fee of 10 Euro and a monthly after-tax income of 2000 Euro, this corresponds to an elasticity of call demand with respect to the subscription fee of approximately $0.1 .^{3}$ Thus, a 20

\footnotetext{
${ }^{1}$ Under profit neutrality, network operators should not oppose lowering termination rates at the regulator's request. This is not how operators usually respond to tighter regulation. Sweden constitutes an illustrative case in point. In 2004, the Swedish telecoms regulator, PTS, deemed all four mobile operators, TeliaSonera, Tele2, Vodafone (later Telenor) and Hi3G, to have significant market power. PTS instructed the operators to lower their termination rates and has continued to do so every consecutive summer since then. The operators consistently refused to comply during the first three years of the new regulatory regime. The only exception was TeliaSonera which voluntarily lowered the rate on one occasion, in 2007. The termination rate disputes have been settled in court from 2008 and onwards, with final rulings being in favour of PTS on every account. Apparently, the operators have given up the fight: Since 2008, they have only sporadically refused to lower their termination rates in accordance with PTS' demands.

${ }^{2}$ I have not found any studies of mobile call demand using household data which report income elasticities. Danaher (2002) estimates a positive and significant income effect in a field experiment introducing a new subscription service similar to a cellular telephone service. Grajek and Kretschmer (2009) estimate a positive and significant relationship between mobile usage intensity and GDP per capita in a panel data analysis of 41 countries. Karacuka et al. (2011) find the same result in a study of the Turkish market for mobile telephony.

${ }^{3}$ Let $\eta_{I}$ be the income elasticity of call demand, and denote by $\eta_{T}=\eta_{I} T / I$ (the absolute value of) the elasticity
} 
percent reduction in the subscription fee would increase call demand by 2 percent. The average residential mobile subscriber in Sweden makes approximately 140 call minutes per month (Table 18 in PTS, 2012), a 2 percent increase of which amounts to 2.8 minutes. The average length of a mobile call is 2.6 minutes (Table 19 in PTS, 2012). Hence, a reduction in the monthly subscription fee from 10 to 8 Euro would cause the average Swedish subscriber to make one additional mobile call per month, with the estimated subscription elasticity of 0.1 . This sounds plausible. Observe, however, that most of my results rest upon the assumption of a positive income effect, not that it is particularly strong.

Considering income effects is policy relevant. Based on the results of the workhorse model, one would conclude that the conditions for efficient regulation are favourable. Policy makers could implement the first-best welfare optimum by means of a simple cost-based regulation: Disallow termination-based discrimination and demand termination rates equal to reported marginal termination cost. As operators do not care about the termination rate under nondiscriminatory contracts, they have no incentive to lie about their marginal cost, either. This paper shows that regulated networks instead have an incentive to strongly exaggerate marginal costs under cost-based regulation, even for weak income effects. A well-designed regulatory policy must take these incentives into account instead of accepting reported costs at face value.

Non-discriminatory contracts Network operators compete for subscribers by offering a call allowance in return for a subscription fee. The equilibrium subscription fee depends on the intensity of network competition as measured by the semi-elasticity of subscription demand. The elasticity falls when income is higher because a reduction in the subscription fee is less valuable to consumers when marginal utility of income is smaller. Therefore, network competition is softer and subscription fees higher when income is higher. A higher profit per subscriber implies that the benefit of attracting additional subscribers by increasing the call allowance is higher. Hence, equilibrium call volumes are also higher when income is higher. In contrast, equilibrium subscription fees and call volumes are independent of income in the workhorse model.

Unregulated network operators trade off user costs against subscription fees in their choice of termination rate. Network operators increase the perceived marginal call costs by agreeing on a higher termination rate because a fraction of calls are terminated in the competitor's network. This serves to reduce equilibrium call allowances. Smaller call allowances, in turn, reduce user costs which reduce the equilibrium subscription fee. The two effects cancel out in the workhorse model, leaving industry profit unaffected by changes in the termination rate.

Income effects open a channel through which higher termination rates soften network competition. Residual income is higher when the termination rate is higher because of the reduction in the subscription fee. A higher residual income implies a smaller subscription elasticity by which the subscription fee falls less than proportionally to the user cost when the termination rate increases. Profit neutrality is a knife-edge result, so an infinitesimal income effect is enough to tilt networks to favour very high termination rates. Regulation is called for because unregulated networks negotiate a reciprocal termination rate in excess of the social optimum.

of call demand with respect to the subscription fee, $T$. If $\eta_{I}=20, T=10$, and $I=2000$, then $\eta_{T}=0.1$. 
Termination-based discrimination Consumers do not care about the size of the network they belong to when all calls are treated the same. But size becomes important for the choice of network whenever operators discriminate between calls inside and outside the network. If on-net call volumes are larger than off-net call volumes, for example because on-net calls are cheaper, then consumers are drawn to the largest network. Cutting the subscription fee becomes extra profitable to the individual operator in this case of tariff-mediated network externalities (Laffont, Rey and Tirole, 1998b) because increased network size attracts additional customers through a network multiplier. In fact, the multiplier is double because a corresponding negative externality arises in the competing network as that network becomes smaller. But tariff-mediated network externalities simply reinforce network competition if the market size is constant, which drives down equilibrium subscription fees at the loss of the industry.

Tariff-mediated network externalities present a motive for network operators to decrease the termination rates because lower termination rates reduce the difference between on-net and offnet call volumes and thereby weaken the network multiplier. This incentive is dominating if the income effect is weak, causing unregulated networks to negotiate a termination rate below cost. Network externalities matter relatively less for consumer choice when networks are differentiated. In this case, positive income effects are sufficient to induce unregulated networks to negotiate a termination rate above cost.

Second-degree price discrimination Network operators often sell subscriptions featuring on-net/off-net discrimination alongside non-discriminatory contracts. Presumably, these menus of contracts exist to account for consumer heterogeneity. Furthermore, incomplete information about consumer preferences requires retail contracts to be incentive compatible. In this model, the contract with on-net/off-net discrimination is designed for informed consumers. An informed consumer is someone who knows whether the call recipient belongs to the own network or not. The non-discriminatory contract is intended for uninformed consumers, i.e. those with no information about the network to which the call recipient belongs. ${ }^{4}$ If the share of informed consumers is large enough, then the incentive problem facing network operators is how to design contracts to prevent informed consumers from deviating to the non-discriminatory contract.

Consumer net surplus is entirely determined by the value of the non-discriminatory contract and independent of network size if the incentive compatibility (IC) constraint of the onnet/off-net contract is binding. But then an operator cannot lower its subscription fee and take advantage of the negative network externality in the competing network present under termination-based price discrimination. Hence, the network multiplier is smaller and network competition softer under second-degree price discrimination. This is true even if the share of consumers on on-net/off-net contracts is large, because IC constraints are binding at the indi-

\footnotetext{
${ }^{4}$ The segmentation of consumers according to their degree of information about call recipients has real-world applications. For example, the Swedish mobile operator Tele2 recommends its on-net/off-net contract "Kompis" to consumers with many friends within the Tele2 network. Tele2 marketed their non-discriminatory contract "Snackis" with the argument that it was appropriate for consumers with no idea about the mobile operators to which their friends belonged (www.tele2.se, March 8, 2013). "Snackis" has since then been replaced by another non-discriminatory contract, "Smart".
} 
vidual consumer level. The reduction in the network multiplier implies that the marginal impact of a higher termination rate on the intensity of network competition is much smaller than under termination-based price discrimination, which drives up operators' preferred termination rate.

Asymmetric information gives rise to an incentive correction whereby the on-net/off-net subscription fee is reduced and the non-discriminatory fee increased to restore incentive compatibility. This incentive correction is mainly achieved by a reduction in the on-net/off-net fee if the subscription demand of uninformed consumers is relatively elastic compared to that of informed consumers, so that the pass-through rate (Weyl and Fabinger, 2013) to the non-discriminatory fee is small. Network operators then extract consumer surplus by reducing the incentive correction. The means to reducing the incentive correction is by way of a higher termination rate which decreases the call allowance in the non-discriminatory contract and, by implication, the value to the informed consumer of deviating to the non-discriminatory contract. Softer network competition and marginal surplus extraction make it profitable for network operators to increase the termination rate above cost under second-degree price discrimination even for weak income effects and independently of network differentiation.

\section{Related literature}

The workhorse, A-LRT, model of network competition was developed by Armstrong (1998) who considered linear non-discriminatory call prices, and Laffont, Rey and Tirole (1998a and b) who also allowed two-part call tariffs and price discrimination. The network competition literature is now extensive, see Armstrong (2002) and Vogelsang (2003) for surveys of the earlier literature, but until now only two papers have provided possible solutions to both the profit neutrality puzzle and the off-net puzzle.

Armstrong and Wright (2009) consider network arbitrage as their main mechanism. Two mobile operators prefer mobile-to-mobile (M2M) termination rates below cost to soften network competition. However, they would both like to exercise vertical market power against a third, fixed-line network by setting high fixed-to-mobile (F2M) termination rates. If the fixed-line operator can bypass termination by transiting calls via the competitor's mobile network, then it is impossible to uphold different termination rates. All termination is priced above cost if fixed-line termination profit is sufficiently important to mobile operators. This result extends trivially to non-discriminatory call prices because then mobile operators do not care about M2M rates, but still care about F2M rates. Even the slightest arbitrage possibility would therefore cause M2M rates to jump to the level of the F2M rate.

Jullien et al. (2013) consider heterogenous call volumes and elastic total subscription demand as their main mechanism. "Light" users hold subscriptions mainly because they value receiving calls and have price elastic total demand. Aggregate demand of "heavy" users (those who initiate calls) is constant. The presence of light users softens competition for heavy users because a heavy user in the competitor's network generates a larger termination profit than a heavy user in the own network. Network operators then agree on termination rates above cost under 
non-discriminatory prices. ${ }^{5}$ The authors show in an example that the same result holds in a range of the parameter space when networks apply termination-based price discrimination. The present paper differs from Armstrong and Wright (2009) and Jullien et al. (2013) in examining a mechanism whereby income effects in subscription and call demand play an important role for the choice of termination rates.

Dessein (2003) conducts the first analysis of network competition with second-degree price discrimination. Consumers differ in terms of volume demand, and operators screen them through a menu of contracts with call allowances and subscription fees. Profit turns out to be independent of the termination rate also under second-degree price discrimination. ${ }^{6}$ Dessein (2004) then introduces additional heterogeneity into the model by also allowing perceived network differentiation to vary between heavy and light users. ${ }^{7}$ Network operators now benefit from a termination rate above (below) cost if heavy users view networks as more (less) differentiated than light users do. The present analysis complements Dessein (2003, 2004) by considering menus that include contracts with on-net/off-net discrimination. Networks prefer a termination rate at or below marginal termination cost if marginal utility of income is constant and the same for all consumers (as in A-LRT). But if on-net/off-net consumers have a large network (so that they make comparatively more calls, all else equal) and their marginal utility of income is relatively low, then network operators profit from increasing the termination rate above cost. Introducing income effects by allowing marginal utility of income to vary across consumers plays the same role in the present context as allowing network differentiation to vary across consumers in Dessein's (2004) model, namely by allowing the elasticity of subscription demand to vary between consumers. Hence, the overall insight is that the profit neutrality puzzle and the off-net puzzle are robust to second-degree price discrimination alone, but are both resolved if the subscription demand of heavy users is inelastic relative to that of light users. But the present analysis is not a straightforward extension of Dessein $(2003,2004)$ and others. A crucial feature of second-degree price discrimination here is the binding IC constraint on the on-net/off-net contract which substantially reduces network effects. Softer network competition renders small degrees of consumer heterogeneity sufficient to tip network preferences in favour of termination rates above cost.

Hurkens and López (2013) assume that consumers do not take the effect of a price increase on network size into account when they select to which network to subscribe. Network externalities disappear under passive expectations, so the termination rate is set to maximize termination profit. ${ }^{8}$ Network externalities are weaker than in A-LRT even in the present model, but in my

\footnotetext{
${ }^{5}$ Dessein (2003) and Armstrong and Wright (2009) allow elastic total subscription demand and find that it is more profitable to lower the termination rate slightly below marginal cost than to increase it marginally.

${ }^{6}$ See also Hahn (2004).

${ }^{7}$ Call allowances and subscription fees are increasing in income in the present model. One interpretation of Dessein's $(2003,2004)$ model would be to assume that consumers differ in terms of income and that marginal utility of income is decreasing. Networks then screen higher (lower) income groups by offering them contracts with larger (smaller) call allowances and higher (lower) subscription fees.

${ }^{8}$ An intermediate stance is to assume that only a share of consumers have passive beliefs. Hoernig (2012) finds the profit-maximizing termination rate to be above cost if and only if at least half of the consumers have passive expectations. Another way of softening network externalities is to assume that every subscriber only takes the actions of some other customers into account - consumers belong to so-called "calling clubs" (Calzada and
} 
case this is due to a binding incentive constraint which renders consumer net surplus independent of network size, and not passive expectations. ${ }^{9}$

\section{Non-discriminatory contracts: The profit neutrality puzzle}

The model A continuum of consumers are uniformly distributed on the unit interval. Each consumer subscribes to at most one of two networks located at each end of the interval. Network $i=1,2$ offers a non-discriminatory retail contract $\left\{x_{i}, T_{i}\right\}$, where $x_{i} \geq 0$ is the number of calls the subscriber is allowed to make to each member of her personal network, independently of whether the call is terminated internally (on-net) or in the competitor's network (off-net), and $T_{i}$ is the subscription fee. ${ }^{10}$

A consumer located at $k \in[0,1]$ derives utility

$$
v_{0}+(1-\theta) \lambda u\left(x_{i}\right)+z\left(I-T_{i}\right)-\frac{1}{2 \sigma}\left|k-k_{i}\right|
$$

from subscribing to network $i$. Call utility $u(\cdot)$ is twice continuously differentiable, strictly increasing and strictly concave on the interval $[0, \bar{x}]$, and weakly decreasing thereafter. ${ }^{11}$ The parameter $1-\theta \in(0,1]$ measures the total size of the network, while $\lambda \in(0,1]$ measures the size of the personal network. Setting $\lambda<1$ is a simple way of capturing the fact that consumers have a personal network which is (much) smaller than the total network. ${ }^{12}$ The utility $z(\cdot)$ of consuming the numeraire good $y$ is twice continuously differentiable, strictly increasing and weakly concave on the interval $[0, I]$, where $I$ denotes income. ${ }^{13}$ A-LRT features quasi-linear utility: $z(y)=y$, and $I$ is large. $\left|k-k_{i}\right|$ is the virtual distance from network $i$, while $1 / 2 \sigma$ is

Valletti, 2008; Gabrielsen and Vagstad, 2008; Hoernig et al., 2013). The smaller is the calling club, the weaker is the network externality and the higher is the termination rate. But the policy implications do not change: The regulator can easily implement the first-best welfare optimum under passive beliefs or in the presence of calling clubs by prohibiting termination-based price discrimination and enforcing cost-based regulation of termination rates. Expectations about network size and calling clubs do not matter under non-discriminatory prices. Network operators then have no incentive to distort the termination rate.

${ }^{9}$ Other extensions of the model have also been considered: Call externalities neither solve the profit neutrality puzzle, nor the off-net puzzle (Armstrong, 2002; Jeon et al., 2004; Berger, 2005; Hurkens and López, 2010). Calzada and Valletti (2008) and López and Rey (2012) find that termination rates above cost can sometimes be used to deter entry under termination-based price competition, but not under non-discriminatory call prices; for this later point, see also Carter and Wright (2003). Valletti and Cambini (2005) argue that networks might prefer termination rates above cost to curb investments in quality improvement under non-discriminatory prices.

${ }^{10} \mathrm{~A}$ call allowance paired with a subscription fee is a common type of retail contract. Considering this type of contract considerably simplifies the analysis without having any qualitative consequences. For example, all results of this section and the next go through with two-part call tariffs (Tangerås, 2014), which is the kind of contract usually considered in the literature.

${ }^{11}$ Call saturation at $\bar{x}$ implies that consumers would make a finite number of calls even with an infinite call allowance. An obvious justification for call saturation is an opportunity cost of time. Call saturation plays a role for the existence and uniqueness proofs, but not otherwise; $\bar{x}$ is large enough to be non-binding at equilibrium.

${ }^{12}$ The important thing to note here about total network size $1-\theta$ is that it is constant. Parametrizing network size facilitates the comparison with second-degree price competition considered in Section 5 . The only role played by the size of the personal network is to establish the existence and uniqueness of a retail equilibrium (for $\lambda$ sufficiently small).

${ }^{13}$ Additively separable utility in $x$ and $y$ is a simplifying, but not crucial assumption. Tangerås (2014) shows that the main results of this section go through even with non-separable utility $V(x, y ;(1-\theta) \lambda)$ if $V$ satisfies appropriate regularity conditions. 
a virtual transportation cost and a measure of horizontal differentiation. The smaller is $\sigma$, the more differentiated are the networks. I assume that the utility $v_{0}$ of holding a subscription (the value of receiving calls, mobile internet access, and so forth) is exogenous, the same for both networks and high enough that all consumers subscribe to one of the two networks.

If both networks have a positive market share and the market is fully covered, then subscription demand for network $i \neq j=1,2$ is given by

$$
s_{i}=(1-\theta)\left[\frac{1}{2}+\sigma\left((1-\theta) \lambda\left(u\left(x_{i}\right)-u\left(x_{j}\right)\right)+z\left(I-T_{i}\right)-z\left(I-T_{j}\right)\right)\right]
$$

as a function of call allowances and subscription fees. Each network operator derives its profit

$$
\Pi_{i}=\underbrace{s_{i}\left(T_{i}-f-c(1-\theta) \lambda x_{i}\right)}_{\text {Subscription profit }}+\underbrace{s_{i} s_{j}\left(a-c_{T}\right) \lambda\left(x_{j}-x_{i}\right)}_{\text {Termination profit }}
$$

from two sources. Network $i$ makes a subscription profit if the subscription fee exceeds user cost, which is the sum of the direct subscription cost, $f$, and the call cost per subscriber, $c(1-\theta) \lambda x_{i}$. Marginal call cost is constant and equal to $c=c_{O}+c_{T}$, where $c_{O}\left(c_{T}\right)$ is the marginal cost of call origination (termination). The second term in $\Pi_{i}$ is termination profit. It is the profit of terminating incoming off-net calls minus the termination cost of outgoing off-net calls. Termination profit is positive if the reciprocal termination rate $a$ is higher than marginal termination cost, and the network receives more off-net calls than it produces, so that $x_{j}>x_{i}$.

Retail equilibrium Network $i$ obtains a higher subscription markup by increasing its subscription fee, but experiences a corresponding loss in subscribers. This is marginal subscription profit below:

$$
\frac{\partial \Pi_{i}}{\partial T_{i}}=\underbrace{s_{i}+\frac{\partial s_{i}}{\partial T_{i}}\left(T_{i}-f-c(1-\theta) \lambda x_{i}\right)}_{\text {Marginal subscription profit }}+\underbrace{\left(\frac{\partial s_{i}}{\partial T_{i}} s_{j}+s_{i} \frac{\partial s_{j}}{\partial T_{i}}\right)\left(a-c_{T}\right) \lambda\left(x_{j}-x_{i}\right)}_{\text {Marginal termination profit }} .
$$

Marginal termination profit depends on marginal termination demand, which is ambiguous. It tends to fall with an increase in the subscription fee because there are fewer subscribers to reach in network $i$, but it also tends to increase because there are now more subscribers calling from the other network. With full market coverage and a balanced call pattern, marginal termination demand is positive if and only if network $i$ initially has more than 50 percent of the subscribers: $\frac{\partial s_{i}}{\partial T_{i}} s_{j}+s_{i} \frac{\partial s_{j}}{\partial T_{i}}=\frac{\partial s_{i}}{\partial T_{i}}\left(s_{j}-s_{i}\right)$. Lemma 1 characterizes the retail equilibrium (subscripts $a$ and $I$ denote partial derivatives with respect to the termination rate and income throughout):

Lemma 1 Assume that both network operators offer non-discriminatory retail contracts. There exists a unique and symmetric retail equilibrium $\left\{x^{*}, T^{*}\right\}$ characterized by

$$
\frac{u^{\prime}\left(x^{*}\right)}{z^{\prime}\left(I-T^{*}\right)}=c+\frac{1}{2}\left(a-c_{T}\right)
$$




$$
T^{*}-f-c(1-\theta) \lambda x^{*}=\frac{1}{2 \sigma z^{\prime}\left(I-T^{*}\right)}
$$

if either (i) networks are differentiated ( $\sigma$ is small); (ii) the termination rate is close to marginal termination cost $\left(\left|a-c_{T}\right|\right.$ is small) or (iii) each subscriber calls a small fraction of the total network ( $\lambda$ is small). The call allowance and the subscription fee are strictly decreasing in the termination rate $\left(x_{a}^{*}<0\right.$ and $\left.T_{a}^{*}<0\right)$ and weakly increasing in income $\left(x_{I}^{*} \geq 0\right.$ and $\left.1>T_{I}^{*} \geq 0\right)$.

Proof: The existence and uniqueness proofs are standard; see Tangerås (2014) for the details. Differentiation of the equilibrium conditions (3) and (4) yields

$$
\begin{array}{ll}
x_{a}^{*}=\Psi\left(\frac{z^{\prime \prime}}{4 \sigma z^{\prime}}-\frac{z^{\prime}}{2}\right), & T_{a}^{*}=-\frac{1}{2} \Psi c(1-\theta) \lambda z^{\prime}, \\
x_{I}^{*}=-\Psi \frac{u^{\prime} z^{\prime \prime}}{z^{\prime}}, & T_{I}^{*}=-\Psi\left(u^{\prime} c(1-\theta) \lambda-\frac{u^{\prime \prime}}{2 \sigma z^{\prime}}\right) \frac{z^{\prime \prime}}{z^{\prime}},
\end{array}
$$

where $\Psi^{-1}=u^{\prime \prime} z^{\prime \prime} / 2 \sigma\left(z^{\prime}\right)^{2}-u^{\prime} c(1-\theta) \lambda z^{\prime \prime} / z^{\prime}-u^{\prime \prime}>0$. Note that $1-T_{I}^{*}=-\Psi u^{\prime \prime}$.

The profit maximizing call allowance is set at the point at which the marginal rate of substitution between calls and the numeraire good is equal to perceived marginal call cost, $c+\left(a-c_{T}\right) / 2$. A small increase in the call allowance, $x$, has value $(1-\theta) \lambda u^{\prime}$ to every consumer in the network. This allows the network operator to raise its subscription fee by $(1-\theta) \lambda u^{\prime} / z^{\prime}$ and keep all consumers equally well off as before. The market shares remain unchanged, so the manipulation is profitable if the increase in the subscription fee outweighs the perceived marginal call cost: $u^{\prime} / z^{\prime}>c+\left(a-c_{T}\right) / 2$. In the opposite case, the network operator strictly profits from reducing the call allowance to save on the perceived call cost. The equilibrium condition (3) implies that the call allowance is set at the efficient level if and only if termination is priced at marginal cost, so that the perceived and the actual marginal call cost are the same and equal to $c$.

The equilibrium subscription fee balances a higher subscription markup against lower subscription demand. Marginal termination profit in (2) is zero at symmetric call allowances. The semi-elasticity of subscription demand

$$
-\left.\frac{\partial s_{i}}{\partial T_{i}} \frac{1}{s_{i}}\right|_{x_{1}=x_{2}=x^{*}, T_{1}=T_{2}=T^{*}}=2 \sigma z^{\prime}\left(I-T^{*}\right)
$$

is a measure of the intensity of network competition at equilibrium. The lower is the subscription semi-elasticity, the higher is the markup of the subscription fee $T^{*}$ over user cost $f+c(1-\theta) \lambda x^{*}$ in (4). Obviously, the semi-elasticity is lower the more differentiated are the networks (the smaller is $\sigma$ ). But the semi-elasticity tends to fall also when income is higher because a reduction in the subscription fee is less valuable to consumers when marginal utility of income is smaller. Softer network competition tends to drive up the equilibrium subscription fee $\left(T_{I}^{*} \geq 0\right)$. With a higher profit per subscriber, it becomes more profitable to attract additional consumers by increasing the call allowance. This is why also the call allowance tends to increase in income $\left(x_{I}^{*} \geq 0\right)$. The call allowance and the subscription fee are strictly increasing in income if and only if marginal utility of income is strictly decreasing $\left(z^{\prime \prime}<0\right)$. This represents the case of positive income 
effects. In the workhorse model, marginal utility of income is constant $\left(z^{\prime \prime}=0\right)$, and the call allowance and the subscription fee are independent of income.

The call allowance falls when the termination rate goes up $\left(x_{a}^{*}<0\right)$ because of an increase in the perceived marginal call cost. User cost $f+c(1-\theta) \lambda x^{*}$ falls when the call allowance falls, and therefore even the subscription fee is lower when the termination rate is higher $\left(T_{a}^{*}<0\right)$. This is the documented "waterbed" effect (Genakos and Valletti, 2011).

Subscription profit is strictly quasi-concave in the own subscription fee, and marginal subscription profit is increasing in the subscription fee of the competitor. Quasi-concavity and strategic complementarity carry over to marginal network profit for $\lambda$ sufficiently small since marginal termination profit is then small in magnitude relative to marginal subscription profit in (2). Hence, $\left\{x^{*}, T^{*}\right\}$ constitutes a unique equilibrium when $\lambda$ is small. For the same reasons, the retail equilibrium is unique also when networks are differentiated ( $\sigma$ is small) or if the termination rate is close to marginal termination cost $\left(\left|a-c_{T}\right|\right.$ is small). These sufficient equilibrium conditions reappear in the remainder of the analysis, so I assume them to hold throughout.

Unregulated termination rates Unregulated network operators negotiate the reciprocal termination rate $a \geq-c_{O}$ to maximize industry profit $(1-\theta) \pi,{ }^{14}$ where

$$
\pi=T^{*}-f-c(1-\theta) \lambda x^{*}=\underbrace{\frac{1}{2 \sigma z^{\prime}\left(I-T^{*}\right)}}_{\text {Subscription elasticity }}
$$

defines industry profit per subscriber. Termination merely represents a redistribution of profit between network operators and therefore cancels out. Industry profit is proportional to the subscription markup by the assumption of constant market size.

A higher termination rate serves to lower the equilibrium subscription fee $\left(T_{a}^{*}<0\right)$, with a negative impact on industry profit, but also reduces the user cost through a smaller call allowance $\left(x_{a}^{*}<0\right)$, which tends to raise industry profit. The total effect is determined by the effect of the termination rate on the intensity of network competition:

$$
\pi_{a}=T_{a}^{*}-c(1-\theta) \lambda x_{a}^{*}=\underbrace{\frac{1}{2 \sigma} \frac{z^{\prime \prime}\left(I-T^{*}\right)}{z^{\prime}\left(I-T^{*}\right)^{2}} T_{a}^{*}}_{\text {Marginal income effect }(+/ 0)}
$$

In the quasi-linear Hotelling framework, network differentiation and marginal utility of income are both constant ( $\sigma$ is constant and $z^{\prime}=1$ ), hence the intensity of network competition is constant; see equation (6). Thus, the marginal effect on the subscription fee and the user cost cancel out, leaving network profit independent of the termination rate in this case. ${ }^{15}$ However,

\footnotetext{
${ }^{14}$ For $a<-c_{O}$, network $i$ could make infinite profits by initiating an unbounded amount of off-net calls. Hence, $a \geq-c_{O}$ to avoid arbitrage.

${ }^{15}$ Profit neutrality also holds in the more general case of constant marginal utility of income different from unity, $z(y)=\beta y$, because then $\pi=1 / 2 \sigma \beta$, which is still independent of $a$. More generally, all quasi-linear models in which subscription demand is determined by the difference in consumer net surplus, i.e. $s_{i}=g\left(v_{i}-v\right)$, feature a constant semi-elasticity, $g^{\prime}(0) / g(0)$, at symmetric contracts and therefore imply profit neutrality. The random
} 
with positive income effects $\left(z^{\prime \prime}<0\right)$, the intensity of network competition falls when the termination rate goes up: A higher termination rate means a lower subscription fee and, consequently, a lower marginal utility of income. The subscription semi-elasticity falls when marginal utility of income falls. Owing to softer network competition, the subscription fee falls disproportionately to the user cost, and the total effect on network profit of a higher termination rate is positive.

Proposition 1 Assume that both network operators offer the non-discriminatory retail contract characterized in Lemma 1.

1. Network profit is independent of the termination rate if and only if the marginal income effect is zero $\left(\pi_{a}=0\right.$ if and only if $\left.z^{\prime \prime}\left(I-T^{*}\right)=0\right)$. This is profit neutrality.

2. Network profit is strictly increasing in the termination rate for any positive marginal income effect $\left(\pi_{a}>0\right.$ if $\left.z^{\prime \prime}\left(I-T^{*}\right)<0\right)$.

Profit neutrality is a knife-edge result and crucially hinges on the semi-elasticity of subscription demand being constant at symmetric retail contracts. It breaks in the presence of even the slightest income effect because the semi-elasticity and therefore the intensity of network competition then depend on the subscription fee. Even a weak income effect has a strong effect on the choice of termination rate. Instead of being indifferent, operators would now like to set the termination rate as high as possible. ${ }^{16}$ However, this does not mean that the termination rate will be infinite. The upper bound on the termination rate is the point at which each network would instead deviate and corner the market. For a sufficiently high, Lemma 1 breaks down and network profit is no longer given by (6); see Laffont, Rey and Tirole (1998a) for the formal proof in the quasi-linear case.

Social welfare Proposition 1 establishes that unregulated networks maximize the termination rate. Whether this incentive renders regulatory intervention desirable depends on the profit maximizing termination rate relative to the social optimum. Under the assumption of unregulated retail competition, the social planner chooses the termination rate $a$ to maximize the sum of consumer net surplus and industry profit per subscriber

$$
w=(1-\theta) \lambda u\left(x^{*}\right)+z\left(I-T^{*}\right)+\pi .
$$

utility model first used by Dessein (2003) for the duopoly case and later extended by Calzada and Valletti (2008) to the general $n \geq 2$ network case also belongs to this class of models: $s_{i}=1 /\left(1+(n-1) e^{-\frac{1}{\gamma}\left\{v_{i}-v\right\}}\right)$. However, profit neutrality does not imply that subscription demand is a function of the differences $v_{i}-v$ in consumer net surplus. For example, $s_{i}=g\left(\left(v_{i} / v\right)^{v}-1\right)$ has a constant semi-elasticity, $g^{\prime}(0) / g(0)$, at symmetric contracts, but is not a function of $v_{i}-v$.

${ }^{16}$ Note also that network profit is strictly increasing in income if income effects are positive, but independent of income if income effects are zero: $\pi_{I}=-\left(1-T_{I}^{*}\right) z^{\prime \prime} / 2 \sigma\left(z^{\prime}\right)^{2}$. Röller and Waverman (2001) show that telecoms investments are significant determinants of economic growth. The above result shows that economic growth can have a positive impact on network profit, even in mature (in the sense of full market coverage) telecoms markets. 
The socially optimal termination rate $a^{\text {opt }}$ trades off efficiency against redistribution because a termination rate different from the marginal termination cost $\left(a \neq c_{T}\right)$ distorts call allowances and redistributes income between consumers and network operators:

$$
\begin{aligned}
w_{a} & =(1-\theta) \lambda u^{\prime}\left(x^{*}\right) x_{a}^{*}-z^{\prime}\left(I-T^{*}\right) T_{a}^{*}+\pi_{a} \\
& =\underbrace{\frac{\lambda}{2}(1-\theta) z^{\prime}\left(I-T^{*}\right)\left(a-c_{T}\right) x_{a}^{*}}_{\text {Call distortion }}-\underbrace{\left(z^{\prime}\left(I-T^{*}\right)-1\right) \pi_{a}}_{\text {Redistribution }} .
\end{aligned}
$$

If marginal utility of income is high enough, i.e. $z^{\prime}\left(I-T^{*}\left(c_{T}\right)\right) \geq 1$, it is social optimal to extract profit from network operators and redistribute it to consumers. This is achieved by setting a termination rate below marginal termination cost. Conversely, the social planner allows upward distortions in the termination rate so as to transfer income to the networks if consumers' marginal utility of income is low, i.e. $z^{\prime}\left(I-T^{*}\left(c_{T}\right)\right)<1$. Even so, there is an upper bound $\bar{a}$ to the termination rate beyond which the social cost of call distortions dominates any welfare benefits of redistribution:

Proposition 2 Assume that both network operators offer the non-discriminatory retail contract characterized in Lemma 1.

1. If $z^{\prime}\left(I-T^{*}\left(c_{T}\right)\right) \geq 1$, then the socially optimal termination rate $a^{\text {opt }}$ is at or below marginal termination $\operatorname{cost} c_{T}$.

2. If $z^{\prime}\left(I-T^{*}\left(c_{T}\right)\right)<1$, then $a^{\text {opt }} \in\left(c_{T}, \bar{a}\right]$, where $\bar{a}>c_{T}$ is defined by $z^{\prime}\left(I-T^{*}(\bar{a})\right)=$ $c /\left(c+\frac{1}{2}\left(\bar{a}-c_{T}\right)\right)$.

Proof: In the Appendix.

Propositions 1 and 2 jointly present a case for regulation under non-discriminatory retail contracts. Unregulated networks would maximize the termination rate, whereas there is an upper bound $\bar{a}$ to the socially optimal termination rate. This holds for any positive income effect. Whether termination should be priced above or below marginal cost at social optimum, depends on the marginal utility of income, $z^{\prime}\left(I-T^{*}\left(c_{T}\right)\right)$, which can be difficult to gauge in practice. However, in the plausible case of consumer surplus weighing more heavily in the social welfare function than firm profit $\left(z^{\prime}\left(I-T^{*}\left(c_{T}\right)\right) \geq 1\right)$, the social optimum is close to or below marginal termination cost.

A second implication of the analysis is that network operators have an incentive to strongly exaggerate costs under cost-based regulation of termination rates. Thus, regulatory authorities should view self-reported costs with skepticism. A solution would be to set a rate ceiling which is independent of self-reported costs, but instead targeted to some retail price index adjusted for technological development - the well-known RPI-X scheme. 


\section{Termination-based discrimination: The off-net puzzle}

The model I now generalize the model in the previous section by allowing operators to discriminate between on-net and off-net calls. Network $i$ offers an on-net/off-net contract $\left\{q_{i}, \widehat{q}_{i}, \widehat{T}_{i}\right\}$, where $q_{i}\left(\widehat{q}_{i}\right)$ is the number of on-net (off-net) calls the subscriber is allowed to make to each member of her personal network, and $\widehat{T}_{i}$ is the subscription fee. ${ }^{17}$

A consumer located at $k \in[0,1]$ derives utility

$$
v_{0}+\widehat{s}_{i} \lambda u\left(q_{i}\right)+\left(\theta-\widehat{s}_{i}\right) \lambda u\left(\widehat{q}_{i}\right)+z\left(I-\widehat{T}_{i}\right)-\frac{1}{2 \sigma}\left|k-k_{i}\right|
$$

from subscribing to network $i$ when the market is fully covered, and the mass of consumers is $\theta \in(0,1]$. Termination-based discrimination creates network externalities in the sense that the value of belonging to a network now also depends on the size $\widehat{s}_{i}$ of the network and not only on the tariff structure. If the on-net call allowance is larger than the off-net call allowance, the value of subscribing to network $i$ increases when network $i$ is larger.

In a rational expectations equilibrium where both networks have a positive market share,

$$
\widehat{s}_{i}=\frac{\frac{\theta}{2}+\theta \sigma\left(\theta \lambda u\left(\widehat{q}_{i}\right)-\theta \lambda u\left(q_{j}\right)+z\left(I-\widehat{T}_{i}\right)-z\left(I-\widehat{T}_{j}\right)\right)}{1-\theta \sigma \lambda\left(u\left(q_{i}\right)-u\left(\widehat{q}_{i}\right)+u\left(q_{j}\right)-u\left(\widehat{q}_{j}\right)\right)}
$$

defines subscription demand as a function of call allowances and subscription fees.

The qualitative difference between network profit

$$
\widehat{\Pi}_{i}=\underbrace{\widehat{s}_{i}\left[\widehat{T}_{i}-f-c \lambda\left(\widehat{s}_{i} q_{i}+\widehat{s}_{j} \widehat{q}_{i}\right)\right]}_{\text {Subscription profit }}+\underbrace{\widehat{s}_{i} \widehat{s}_{j}\left(a-c_{T}\right) \lambda\left(\widehat{q}_{j}-\widehat{q}_{i}\right)}_{\text {Termination profit }}
$$

under termination-based discrimination and network profit $\Pi_{i}$ under non-discriminatory contracts is that the call cost here is the weighted average of the on-net and off-net call volumes.

Retail equilibrium The marginal effect on profit of increasing the subscription fee $\widehat{T}_{i}$ equals:

$$
\frac{\partial \widehat{\Pi}_{i}}{\partial \widehat{T}_{i}}=\underbrace{\widehat{s}_{i}+\frac{\partial \widehat{s}_{i}}{\partial \widehat{T}_{i}}\left(\widehat{T}_{i}-f-c \lambda\left(\widehat{s}_{i} q_{i}+\widehat{s}_{j} \widehat{q}_{i}\right)\right)}_{\text {Marginal subscription profit }}+\underbrace{\frac{\partial \widehat{s}_{i}}{\partial \widehat{T}_{i}}\left(\widehat{s}_{j}-\widehat{s}_{i}\right)(a-c T) \lambda\left(\widehat{q}_{j}-\widehat{q}_{i}\right)}_{\text {Marginal termination profit }}-\underbrace{\widehat{s}_{i} \frac{\partial \widehat{s}_{i}}{\partial \widehat{T}_{i}} c \lambda\left(q_{i}-\widehat{q}_{i}\right)}_{\text {Composition effect }} .
$$

The first two terms are the same as under non-discriminatory contracts; see equation (2). The final term is new and represents a cost composition effect. As the number of subscribers falls, a larger share of every remaining subscriber's personal network is located off-net. The composition effect is positive if the off-net call allowance is smaller than the on-net call allowance $\left(q_{i}>\widehat{q}_{i}\right)$, which tends to increase the optimal subscription fee.

\footnotetext{
${ }^{17}$ Specifying separate on-net and off-net call allowances is somewhat peculiar, but for simplifying purposes only. The equilibrium on-net/off-net contract can equivalently be reformulated as a two-part tariff with calls priced at their perceived marginal cost.
} 
Lemma 2 Assume that both network operators offer retail contracts with termination-based discrimination. The unique and symmetric retail equilibrium $\left\{q^{*}, \widehat{q}^{*}, \widehat{T}^{*}\right\}$ is characterized by

$$
\begin{gathered}
\frac{u^{\prime}\left(q^{*}\right)}{z^{\prime}\left(I-\widehat{T}^{*}\right)}=c, \frac{u^{\prime}\left(\widehat{q}^{*}\right)}{z^{\prime}\left(I-\widehat{T}^{*}\right)}=c_{O}+a, \\
\widehat{T}^{*}-f-c \theta \lambda q^{*}=\frac{1-2 \sigma \theta \lambda\left(u\left(q^{*}\right)-u\left(\widehat{q}^{*}\right)\right)}{2 \sigma z^{\prime}\left(I-\widehat{T}^{*}\right)} .
\end{gathered}
$$

The on-net call allowance is weakly increasing in the termination rate and income $\left(q_{a}^{*} \geq 0\right.$ and $\left.q_{I}^{*} \geq 0\right)$. The off-net call allowance and the subscription fee are strictly decreasing in the termination rate $\left(\widehat{q}_{a}^{*}<0\right.$ and $\left.\widehat{T}_{a}^{*}<0\right)$ and weakly increasing in income $\left(\widehat{q}_{I}^{*} \geq 0\right.$ and $\left.1>\widehat{T}_{I}^{*} \geq 0\right)$.

Proof: Tangerås (2014) shows that the retail equilibrium exists and is unique if either $\sigma$ is small, $\left|a-c_{T}\right|$ is small or $\lambda$ is small. Differentiation of the equilibrium conditions (11) and (12) yields

$$
\begin{array}{lll}
q_{a}^{*}=-\widehat{\Psi} \theta \lambda c\left(c_{O}+a\right) z^{\prime} z^{\prime \prime}, & \widehat{q}_{a}^{*}=\widehat{\Psi}\left(1-\frac{\psi}{\sigma} z^{\prime \prime}\right) z^{\prime} u^{\prime \prime}, & \widehat{T}_{a}^{*}=\widehat{\Psi} \theta \lambda\left(c_{O}+a\right) z^{\prime} u^{\prime \prime} \\
q_{I}^{*}=\widehat{\Psi} c \widehat{u}^{\prime \prime} z^{\prime \prime}, & \widehat{q}_{I}^{*}=\widehat{\Psi}\left(c_{O}+a\right) u^{\prime \prime} z^{\prime \prime}, & \widehat{T}_{I}^{*}=\widehat{\Psi}\left(\theta \lambda\left(c_{O}+a\right)^{2}-\frac{\psi}{\sigma} \widehat{u}^{\prime \prime}\right) u^{\prime \prime} z^{\prime \prime}
\end{array}
$$

where I have defined $u^{\prime \prime}=u^{\prime \prime}\left(q^{*}\right), \widehat{u}^{\prime \prime}=u^{\prime \prime}\left(\widehat{q}^{*}\right), \psi=\left[1-2 \sigma \theta \lambda\left(u\left(q^{*}\right)-u\left(\widehat{q}^{*}\right)\right)\right] / 2\left(z^{\prime}\right)^{2}>0$ and $\widehat{\Psi}^{-1}=\left(1-\psi \sigma^{-1} z^{\prime \prime}\right) u^{\prime \prime} \widehat{u}^{\prime \prime}+\theta \lambda\left(c_{O}+a\right)^{2} u^{\prime \prime} z^{\prime \prime}>0.1-\widehat{T}_{I}^{*}=\widehat{\Psi} u^{\prime \prime} \widehat{u}^{\prime \prime}>0$.

Same as under non-discriminatory contracts, operators optimally set call allowances to align the marginal rate of substitution between calls and the numeraire good with the perceived marginal call cost, which is $c$ for on-net calls and $c_{O}+a$ for off-net calls under on-net/off-net discrimination. The equilibrium subscription fee balances a higher subscription markup against lower subscription demand, also accounting for the effect of a higher subscription fee on call cost - the composition effect. Marginal termination profit in (10) is zero at symmetric call allowances.

The semi-elasticity of subscription demand

$$
-\left.\frac{\partial \widehat{s}_{i}}{\partial \widehat{T}_{i}} \frac{1}{\widehat{s}_{i}}\right|_{q_{1}=q_{2}=q^{*}, \widehat{q}_{1}=\widehat{q}_{2}=\widehat{q}^{*}, \widehat{T}_{1}=\widehat{T}_{2}=\widehat{T}^{*}}=\frac{2 \sigma z^{\prime}\left(I-\widehat{T}^{*}\right)}{1-2 \sigma \theta \lambda\left(u\left(q^{*}\right)-u\left(\widehat{q}^{*}\right)\right)}
$$

measures the intensity of network competition at equilibrium. The semi-elasticity is lower when network differentiation is higher ( $\sigma$ is smaller) and income is higher, just as in the case of nondiscriminatory contracts. An additional network multiplier, $2 \sigma \theta \lambda\left(u\left(q^{*}\right)-u\left(\widehat{q}^{*}\right)\right)$, comes into play under termination-based discrimination. Recall from equation (9) that the value of subscribing to network $i$ increases in the size of network $i$ if the on-net call allowance is larger than the offnet call allowance. This positive network externality makes it is easier for a network to attract additional consumers by reducing the subscription fee because a higher market share further accentuates the benefit of belonging to that network. Actually, the effect is double because of an additional negative network externality of equal magnitude in the competing network. But in the end, network externalities only serve to intensify competition and drive down the equilibrium 
subscription fee because the size of the market is constant. So the subscription semi-elasticity above is higher when the network multiplier is higher.

The comparative statics results are similar to those under non-discrimination. The call allowances and the subscription fee have a positive income effect if marginal utility of income is strictly decreasing $\left(z^{\prime \prime}<0\right)$, but a zero income effect if marginal utility of income is constant $\left(z^{\prime \prime}=0\right)$ since a higher income (weakly) softens network competition. A higher termination rate drives down the off-net call allowance because of a higher perceived marginal off-net call cost. A lower off-net call allowance reinforces the network multiplier, which intensifies network competition and pushes down the equilibrium subscription fee. The reduction in the subscription markup tends to lower the on-net call allowance, while it tends to be increased by a more intense network competition. The competitive effect dominates if marginal utility of income is strictly decreasing, in which case the on-net call allowance is higher when the termination rate is higher.

Unregulated termination rates Industry profit per subscriber

$$
\widehat{\pi}=\widehat{T}^{*}-f-\frac{\theta \lambda}{2} c\left(q^{*}+\widehat{q}^{*}\right)=\underbrace{\frac{1-2 \sigma \theta \lambda\left(u\left(q^{*}\right)-u\left(\widehat{q}^{*}\right)\right)}{2 \sigma z^{\prime}\left(I-\widehat{T}^{*}\right)}}_{\text {Subscription elasticity }}+\underbrace{\frac{\theta \lambda}{2} c\left(q^{*}-\widehat{q}^{*}\right)}_{\text {Composition effect }}
$$

is proportional to the subscription markup by the assumption of constant market size and because termination profit is zero at the industry level. A new term shows up under terminationbased discrimination. The subscription markup is no longer entirely determined by the intensity of network competition, as measured by the (inverse) subscription semi-elasticity, but also by the cost composition effect. A stronger cost composition effect drives up the equilibrium subscription fee and industry profit.

The first term in marginal profit below is the marginal income effect, which tends to soften network competition and raise industry profit, and is the same as under non-discrimination:

$$
\widehat{\pi}_{a}=\underbrace{\frac{\left[1-2 \sigma \theta \lambda\left(u\left(q^{*}\right)-u\left(\widehat{q}^{*}\right)\right] z^{\prime \prime}\left(I-\widehat{T}^{*}\right)\right.}{2 \sigma z^{\prime}\left(I-\widehat{T}^{*}\right)^{2}} \widehat{T}_{a}^{*}}_{\text {Marginal income effect }(+/ 0)}+\underbrace{\theta \lambda\left(\left(c_{O}+a\right) \widehat{q}_{a}^{*}-c q_{a}^{*}\right)}_{\text {Marginal network effect }(-)}+\underbrace{\frac{\theta \lambda}{2} c\left(q_{a}^{*}-\widehat{q}_{a}^{*}\right)}_{\text {Marginal composition effect }(+)}
$$

A higher termination rate increases the on-net call allowance $\left(q_{a}^{*} \geq 0\right)$ and decreases the offnet call allowance $\left(\widehat{q}_{a}^{*}<0\right)$, with two effects on network profit. First, it amplifies the network multiplier, which intensifies network competition and lowers industry profit. This is the marginal network effect above. Second, it reinforces the composition effect, which drives up the equilibrium subscription fee and industry profit. This is the marginal composition effect above.

The marginal network effect dominates the marginal composition effect for all termination rates above marginal termination cost. Hence, unregulated networks negotiate a termination rate below marginal cost if the marginal income effect is weak enough. On the other hand, the marginal network effect is of relatively less importance for network competition if the networks are differentiated ( $\sigma$ is low). Under these circumstances, network operators soften competition 
and raise profit by negotiating a termination rate above cost.

Proposition 3 Assume that both network operators offer the on-net/off-net retail contract characterized in Lemma 2.

1. The profit maximizing termination rate $\widehat{a}^{*}$ converges to $\left(c_{T}-c_{O}\right) / 2<c_{T}$ as the marginal income effect vanishes $\left(z^{\prime \prime} \rightarrow 0\right)$. This is the off-net puzzle.

2. Unregulated network operators negotiate a termination rate above the marginal cost of termination for any positive marginal income effect if network differentiation is high enough $\left(z^{\prime \prime}<0\right.$ and $\sigma$ small imply $\widehat{\pi}\left(\widehat{a}^{*}\right)>\widehat{\pi}(a)$ for some $\widehat{a}^{*}>c_{T}$ and for all $\left.a \leq c_{T}\right)$.

Proof: The marginal income effect in $\widehat{\pi}_{a}$ above vanishes as $z^{\prime \prime} \rightarrow 0$, so does $q_{a}^{*}$; see (13). Hence, $\widehat{\pi}_{a} \rightarrow \theta \lambda\left(2 a+c_{O}-c_{T}\right) \widehat{q}_{a}^{*} / 2$ as $z^{\prime \prime} \rightarrow 0$, and $\widehat{\pi}$ therefore obtains its global maximum $\widehat{a}^{*}$ at $\left(c_{T}-c_{O}\right) / 2$ in the limit. To see the second result, substitute (13) into $\widehat{\pi}_{a}$ and rearrange terms:

$$
\frac{2 \sigma}{\theta^{2} \lambda z^{\prime}} \widehat{\Psi}^{-1} \widehat{\pi}_{a}=2 \sigma\left(a-c_{T}\right) u^{\prime \prime}+c\left[\psi u^{\prime \prime} z^{\prime \prime}+\sigma u^{\prime \prime}+\theta \sigma \lambda c\left(c_{O}+a\right) z^{\prime \prime}\right] .
$$

The first term on the right-hand side is single-peaked with a global maximum at $a=c_{T}$. The second term is strictly positive for all $a \in\left[-c_{O}, c_{T}\right]$ if $z^{\prime \prime}<0$ and $\sigma$ is small enough.

The first part of Proposition 3 generalizes the result by Gans and King (2001) - that unregulated networks negotiate a termination rate below cost - to the case of weak income effects. But the proposition also sharpens their result by characterizing the profit maximizing termination rate. In the plausible case of the marginal origination and termination cost being the same $\left(c_{O}=c_{T}\right)$, unregulated network competition converges to the Bill-and-Keep regime $\left(\widehat{a}^{*} \rightarrow 0\right)$ in the limit when the income effect vanishes. The second part shows that income effects can resolve the off-net puzzle. If the degree of network differentiation is large relative to the income effect, then unregulated network operators negotiate a termination rate above marginal termination cost.

Social welfare Welfare is the sum of consumer net surplus and industry profit per subscriber:

$$
\widehat{w}=\frac{\theta \lambda}{2}\left(u\left(q^{*}\right)+u\left(\widehat{q}^{*}\right)\right)+z\left(I-\widehat{T}^{*}\right)+\widehat{\pi} .
$$

The socially optimal termination rate $\widehat{a}^{\text {opt }}$ trades off efficiency against redistribution also in the case of termination-based discrimination:

$$
\widehat{w}_{a}=\underbrace{\frac{\theta \lambda}{2} z^{\prime}\left(I-\widehat{T}^{*}\right)\left(a-c_{T}\right) \widehat{q}_{a}^{*}}_{\text {Call distortion }}-\underbrace{\left(z^{\prime}\left(I-\widehat{T}^{*}\right)-1\right) \widehat{\pi}_{a}}_{\text {Redistribution }} .
$$

Regulation is called for because profit maximizing network operators typically fail to appropriately account for the call distortions associated with their choice of termination rate. But unreg- 
ulated termination rates can be too high or too low from society's viewpoint under terminationbased discrimination:

Proposition 4 Assume that both network operators offer the on-net/off-net retail contract characterized in Lemma 2.

1. The unregulated termination rate is below the social optimum, $\widehat{a}^{*}<\widehat{a}^{\text {opt }}$, if the income effect is weak enough ( $z^{\prime \prime}$ is close to zero).

2. The unregulated termination rate is above the social optimum, $\widehat{a}^{*}>\widehat{a}^{\text {opt }}$, for any positive income effect $\left(z^{\prime \prime}<0\right)$ if networks are sufficiently differentiated ( $\sigma$ is low).

Proof: In the Appendix.

If the income effects are weak so that the profit maximizing termination rate is below termination cost, then the regulator can reduce distortions by increasing the termination rate above the profit maximizing level. One way of doing this is to impose a termination rate floor. In the opposite case of unregulated network operators negotiating a termination rate above cost, the regulator can reduce distortions by instead imposing a termination rate ceiling.

\section{Second-degree price discrimination}

The analysis has so far built on the assumption that all consumers are identical - up to a constant measuring horizontal differentiation. Homogeneity implies that network operators only offer one contract each. I now turn to the more compelling case of heterogenous consumers: Some consumers prefer subscriptions with on-net/off-net discrimination, while others prefer contracts in which all calls are equal. Contracts are required to be incentive compatible because operators cannot distinguish ex ante between different types of consumers.

The model There are two types of consumers, informed ones in share $\theta$ and uninformed ones in share $1-\theta$. An informed consumer is someone who knows whether the called party belongs to the own network or is located off-net. An uninformed consumer has no information about the recipient's network. These types are uniformly distributed on the unit interval and statistically independent of one another. Network $i$ designs an on-net/off-net contract $\left\{q_{i}, \widehat{q}_{i}, \widehat{T}_{i}\right\}$ for informed consumers and offers a non-discriminatory contract $\left\{x_{i}, T_{i}\right\}$ intended for uninformed consumers.

I introduce additional heterogeneity by allowing consumers to differ also in terms of their marginal utility of income. Specifically, I assume away income effects for informed consumers. Their utility of consuming the numeraire good equals $y$, the same as in A-LRT. For uninformed consumers, I maintain the more general form $z(y)$. This heterogeneity biases networks to favour termination rates below cost by removing the positive marginal income effect in the segment of informed consumers. 
Under the assumption that consumers only call other consumers of the same type (e.g. Dessein, 2003), the on-net/off-net contract is incentive compatible if and only if

$$
\widehat{v}_{i}=\widehat{v}\left(q_{i}, \widehat{q}_{i}, \widehat{T}_{i}, \widehat{s}_{i}^{m}\right)=\widehat{s}_{i}^{m} \lambda u\left(q_{i}\right)+\left(\theta-\widehat{s}_{i}^{m}\right) \lambda u\left(\widehat{q}_{i}\right)-\widehat{T}_{i} \geq \theta \lambda u\left(x_{i}\right)-T_{i},
$$

where $\widehat{s}_{i}^{m}$ is the number of informed consumers in network $i$. A type dependent call pattern here implies that people only call others with the same marginal utility of income as themselves. A biased call pattern along this dimension arises naturally if marginal utility of income is decreasing and people tend to call members of their own income group more frequently. ${ }^{18}$

An important aspect of second-degree price discrimination in this dimension is that incentive compatibility is affected, not only by the network's own choice of contracts, but also by the contracts offered by the competitor through the network externality. The Revelation Principle does not require $i$ 's contracts to respect the IC constraints of $j$ 's consumers. Rather, it is necessary to account for the possibility of incentive incompatibility in subscription demand. Thus

$$
\widehat{s}_{i}^{m}=\frac{\frac{\theta}{2}+\theta \sigma\left[\lambda \theta u\left(\widehat{q}_{i}\right)-\widehat{T}_{i}-J\left(\lambda \theta u\left(q_{j}\right)-\widehat{T}_{j}\right)-(1-J)\left(\lambda \theta u\left(x_{j}\right)-T_{j}\right)\right]}{1-\theta \sigma \lambda\left[u\left(q_{i}\right)-u\left(\widehat{q}_{i}\right)+J\left(u\left(q_{j}\right)-u\left(\widehat{q}_{j}\right)\right)\right]}
$$

is the number of consumers subscribing to $i$ 's on-net/off-net contract in rational expectations equilibrium when the market is fully covered. The indicator function $J$ takes the value of 1 if $j$ 's on-net/off-net contract is strictly incentive compatible $\left(\widehat{v}_{j}>\theta \lambda u\left(x_{j}\right)-T_{j}\right)$ and the value of 0 if it is instead strictly incentive incompatible $\left(\widehat{v}_{j}<\theta \lambda u\left(x_{j}\right)-T_{j}\right)$. Observe that the intensity of competition for informed consumers as measured by the semi-elasticity $-\left(\partial \widehat{s}_{i}^{m} / \partial \widehat{T}_{i}\right) / \widehat{s}_{i}^{m}$ depends on whether $j$ 's IC constraint is satisfied or not. This has implications for network competition, as we shall see.

Taking the on-net/off-net contract creates a variance in consumer net surplus of the uninformed consumer because she then is incompletely informed about the number of calls available to her (or about total call expenditures under two-part tariffs). Operators offer uninformed consumers non-discriminatory contracts if these subscribers are sufficiently risk averse. ${ }^{19}$ Risk aversion also means that uniformed consumers would hesitate to select an on-net/off-net contract over a non-discriminatory contract. Thus, I neglect the IC constraint on the non-discriminatory contract in what follows, but verify in the Appendix that it is indeed satisfied in the relevant range of termination rates under a consistent set of assumptions. In a fully covered market, demand for network $i$ 's non-discriminatory contract thus equals $s_{i}$, given by equation (1).

\footnotetext{
${ }^{18}$ A type dependent call pattern hugely simplifies the analysis without fundamentally affecting the model. I discuss robustness to alternative call patterns at the end of the section. Marginal utility of income is perfectly correlated with consumers' degree of information about call recipients. Allowing consumers to differ in both dimensions would create a complicated problem of multi-dimensional asymmetric information.

${ }^{19}$ The most extreme manifestation would be lexicographic preferences towards stability in call allowances.
} 
The profit of network $i$ reads

$$
\begin{aligned}
\Pi_{i}^{m} & =\underbrace{\widehat{s}_{i}^{m}\left[\widehat{T}_{i}-f-c \lambda\left(\widehat{s}_{i}^{m} q_{i}+\widehat{s}_{j}^{m} \widehat{q}_{i}\right)\right]+s_{i}\left[T_{i}-f-c(1-\theta) \lambda x_{i}\right]}_{\text {Subscription profit }} \\
& +\underbrace{\left(a-c_{T}\right) \lambda\left[\widehat{s}_{i}^{m} \widehat{s}_{j}^{m}\left(\widehat{q}_{j}-\widehat{q}_{i}+(1-J)\left(x_{j}-\widehat{q}_{j}\right)\right)+s_{i} s_{j}\left(x_{j}-x_{i}\right)\right]}_{\text {Termination profit }}
\end{aligned}
$$

Termination profit is discontinuous. Suppose that the initial contractual offers of both networks are such that the on-net call allowance is higher than the off-net call allowance and that the IC constraint of network $j$ barely holds (so that $J=1$ ). A deviation by network $i$ to a lower on-net/off-net subscription fee creates a negative network externality in network $j$ which leads to a violation of the IC constraint of that network (so that $J=0$ ). As a consequence, incoming off-net traffic in network $i$ shifts discontinuously from $\widehat{q}_{j}$ to $x_{j}$.

The benchmark case of third-degree price discrimination Assume that network operators can observe the different consumer types ex ante. Network profit $\Pi_{i}^{m}$ is then separable in the two retail contracts by the assumption that only consumers of the same type call each other. Consequently, the pair of equilibrium contracts is given by $\left\{x^{*}, T^{*}\right\}$ and $\left\{q^{*}, \widehat{q}^{*}, \widehat{T}^{*}\right\}$ characterized in Lemmas 1 and 2 (recalling the assumption here that $z^{\prime}\left(I-\widehat{T}^{*}\right)=1$ ).

Network operators would like to negotiate a (high) low termination rate to maximize industry profit on the (un)informed segment of subscribers. But they cannot reasonably set different termination rates for different types of consumers, so an increase in the termination rate trades off a stronger network externality against the marginal composition effect and the marginal income effect in the uninformed segment: ${ }^{20}$

$$
\theta \widehat{\pi}_{a}+(1-\theta) \pi_{a}=\frac{\theta^{2} \lambda}{2}\left(c_{O}+2 a-c_{T}\right) \widehat{q}_{a}^{*}+\frac{1-\theta}{2 \sigma} \frac{z^{\prime \prime}\left(I-T^{*}\right)}{z^{\prime}\left(I-T^{*}\right)^{2}} T_{a}^{*}
$$

Marginal income effects in the segment of uninformed consumers drive the profit maximizing termination rate above $\widehat{a}^{*}=\left(c_{T}-c_{O}\right) / 2$ and dominate the trade-off if the share $1-\theta$ of uninformed consumers is large enough. In this case, network operators negotiate a termination rate above cost under third-degree price discrimination. This holds independently of the degree of network differentiation.

Instead, the profit maximizing termination rate is below termination cost in the opposite case when the share $\theta$ of informed consumers is large enough because the marginal network effect then dominates the trade-off. But this result depends crucially on consumer types being observable ex ante. The value $\widehat{v}\left(q^{*}, \widehat{q}^{*}, \widehat{T}^{*}, \theta / 2\right)$ to the informed consumer of her designated on-net/off-net contract falls when the termination rate goes down $\left(\widehat{v}_{a}>0\right.$; see the proof of Proposition 4) because network competition in the on-net/off-net segment is softer when the termination rate is lower. The value of deviating to the non-discriminatory contract increases, however, because

\footnotetext{
${ }^{20}$ The sole purpose of differentiating termination rates along these lines would be to soften network competition and should therefore be prohibited by regulators.
} 
the call allowance is higher and network competition more intense in the non-discriminatory segment when the termination rate is lower. To see this, observe that

$$
\lambda \theta u^{\prime}\left(x^{*}\right) x_{a}^{*}-T_{a}^{*}=\lambda\left(\theta u^{\prime}\left(x^{*}\right)-c(1-\theta)\right) x_{a}^{*}-\pi_{a}
$$

is negative if $\theta$ is high enough. Under reasonable assumptions, therefore, the benchmark contracts $\left\{q^{*}, \widehat{q}^{*}, \widehat{T}^{*}\right\}$ and $\left\{x^{*}, T^{*}\right\}$ cannot be implemented under asymmetric information for termination rates close to or below marginal termination cost:

Lemma 3 The benchmark contracts $\left\{q^{*}, \widehat{q}^{*}, \widehat{T}^{*}\right\}$ and $\left\{x^{*}, T^{*}\right\}$ are incentive incompatible for all termination rates below a threshold $\widehat{a}>c_{T}$ if the share of informed consumers is large enough $\left(\theta \geq \max \left\{\frac{1}{2} ; \frac{2}{2+z^{\prime}\left(I-T^{*}\left(c_{T}\right)\right)}\right\}\right)$ and either the two consumer types are not too different from one another in terms of marginal utility of income $\left(\left|z^{\prime}\left(I-T^{*}\left(c_{T}\right)\right)-1\right|\right.$ is small enough); or $z^{\prime}\left(I-T^{*}\left(c_{T}\right)\right)>1$ and $c \sigma \lambda$ is small enough.

\section{Proof: In the Appendix.}

To understand the nature of network competition when the share of informed consumers is high, it is necessary to take explicit account of the IC constraint (15). ${ }^{21,22}$ The incentive correction

$$
\Phi\left(x^{*}, T^{*}\right)=\theta \lambda\left(u\left(x^{*}\right)-\frac{1}{2} u\left(q^{*}\right)-\frac{1}{2} u\left(\widehat{q}^{*}\right)\right)+\underbrace{\frac{1-2 \sigma \theta \lambda\left(u\left(q^{*}\right)-u\left(\widehat{q}^{*}\right)\right)}{2 \sigma}-\frac{1}{2 \sigma z^{\prime}\left(I-T^{*}\right)}+c \lambda\left(\theta q^{*}-(1-\theta) x^{*}\right)}_{\widehat{T}^{*}-T^{*}}
$$

measures the amount by which the difference, $\widehat{T}^{*}-T^{*}$, in subscription fees would have to be reduced by both network operators to restore incentive compatibility in the benchmark case. The incentive correction affects the optimal retail contracts, so that a retail equilibrium under second-degree price discrimination generally differs from the benchmark contracts. Let $\Phi(x, T)$ be the incentive correction for the non-discriminatory contract $\{x, T\}$.

Retail equilibrium Competition for informed and uninformed consumers is connected through incentive compatibility under incomplete information about consumer preferences. For example,

\footnotetext{
${ }^{21}$ This is not the case when $\theta$ is small. I show in the Appendix that the benchmark contracts satisfy the IC constraint (15) if uninformed consumers are in minority $(\theta<1 / 2)$, their marginal utility of consumption is small enough $\left(z^{\prime}\left(I-T^{*}\left(c_{T}\right) \leq 1\right)\right.$ and the marginal call cost $c$ is small enough. Third-degree price discrimination thus yields insights about the implications of consumer heterogeneity when the share of informed consumers is small, but not when it is large.

${ }^{22} \mathrm{~A}$ relevant question is whether operators could achieve incentive compatibility by specifying contracts in terms of total call allowances instead of individual call allowances as is now the case. The non-discriminatory contract would be unattractive to informed consumers if the share of uninformed consumers, and therefore their total call allowance, was small. First, the results of this section do not hinge on the share of informed consumers being particularly large. It is sufficient that $\theta=1 / 2$ if $z^{\prime}(y)$ is not too small. Second, Tangerås (2014) shows that incentive problems arise even under a type independent call pattern. It does not matter whether contracts are specified in terms of individual or total call allowances when the two groups are of equal size or call patterns are type independent. Third, it may be in the industry's best interest to collectively avoid contracts which costlessly screen consumers because incomplete information softens network competition. I return to this third issue below.
} 
the IC constraint (15) defines the subscription fee of the on-net/off-net contract as a function of the subscription fee of the non-discriminatory contract and call allowances.

Network $i$ maximizes $\Pi_{i}^{m}$ over the retail contracts $\varpi_{i}=\left\{\left(q_{i}, \widehat{q}_{i}, \widehat{T}_{i}\right) ;\left(x_{i}, T_{i}\right)\right\}$ subject to (15). As usual, network $i$ trades off a higher subscription markup against a loss in subscribers at optimum (I have omitted marginal termination profit which is zero at symmetric market shares):

$$
s_{i}+\widehat{s}_{i}^{m} \frac{\partial \widehat{T}_{i}}{\partial T_{i}}+\frac{\partial s_{i}}{\partial T_{i}}\left(T_{i}-f-c(1-\theta) \lambda x_{i}\right)+\frac{\partial \widehat{s}_{i}^{m}}{\partial \widehat{T}_{i}} \frac{\partial \widehat{T}_{i}}{\partial T_{i}}\left(\widehat{T}_{i}-f-2 \widehat{s}_{i}^{m} c \lambda q_{i}\right)=0 .
$$

An increase in the non-discriminatory fee, $T_{i}$, spills over to the segment of informed consumers through the IC constraint $\left(\partial \widehat{T}_{i} / \partial T_{i}>0\right)$.

Lemma 4 The pair of retail contracts $\varpi^{m}=\left\{\left(q^{*}, \widehat{q}^{*}, \widehat{T}^{m}\right) ;\left(x^{m}, T^{m}\right)\right\}$ characterized by call allowances $u^{\prime}\left(q^{*}\right)=c, u^{\prime}\left(\widehat{q}^{*}\right)=c_{O}+a$,

$$
\frac{u^{\prime}\left(x^{m}\right)}{z^{\prime}\left(I-T^{m}\right)}=\frac{c+\frac{1}{2}\left(a-c_{T}\right)}{1-\left(\frac{\theta}{1-\theta} z^{\prime}\left(I-T^{m}\right)-1\right) \frac{\theta \sigma z^{\prime}\left(I-T^{m}\right)\left[(1-\Omega) \theta \lambda\left(u\left(q^{*}\right)-u\left(\widehat{q}^{*}\right)\right)+2 \Phi\left(x^{m}, T^{m}\right)\right]}{\theta+(1-\theta) z^{\prime}\left(I-T^{m}\right)\left[1-\Omega \theta \sigma \lambda\left(u\left(q^{*}\right)-u\left(\widehat{q}^{*}\right)\right)\right]}}
$$

and subscription fees

$$
\begin{aligned}
\widehat{T}^{m}-f-c \theta \lambda q^{*}-\frac{1-2 \sigma \theta \lambda\left(u\left(q^{*}\right)-u\left(\widehat{q}^{*}\right)\right)}{2 \sigma} & \\
& =(1-\Omega) \kappa \frac{\theta \lambda}{2}\left(u\left(q^{*}\right)-u\left(\widehat{q}^{*}\right)\right)-(1-\kappa) \Phi\left(x^{m}, T^{m}\right), \\
T^{m}- & f-c(1-\theta) \lambda x^{m}-\frac{1}{2 \sigma z^{\prime}\left(I-T^{m}\right)} \\
& =(1-\Omega) \kappa \frac{\theta \lambda}{2}\left(u\left(q^{*}\right)-u\left(\widehat{q}^{*}\right)\right)+\kappa \Phi\left(x^{m}, T^{m}\right)
\end{aligned}
$$

represent a symmetric equilibrium under second-degree price discrimination, where $\Omega \in[0,1]$.

Proof: Tangerås (2014) shows that network profit is locally concave if either $\sigma$ is small, $\lambda$ is small or $\theta$ is large and $\left|a-c_{T}\right|$ is small. If also a monotonicity condition $\left(a-c_{T}\right)\left(\widehat{q}^{*}-x^{m}\right) \geq 0$ is satisfied, then network profit is globally concave and existence guaranteed. The monotonicity condition is necessary when the benchmark contracts are incentive incompatible: If $\left(a-c_{T}\right)\left(\widehat{q}^{*}-x^{m}\right)<0$, then each network operator can achieve a discontinuous increase in termination profit by an infinitesimal deviation. In the Appendix, I show that the monotonicity condition as well as the IC constraint of the non-discriminatory contract are satisfied for all $a \in\left[c_{T}, \widehat{a}\right]$ and some $\widehat{a}>c_{T}$ if the share of informed consumers is large enough, i.e. $\theta>\frac{1}{1+z^{\prime}\left(I-T^{*}\left(c_{T}\right)\right)}$, and uninformed consumers' marginal utility of consumption satisfies $z^{\prime}\left(I-T^{*}\left(c_{T}\right)\right) \geq 1$ or is not too far below unity. These conditions are consistent with the assumptions of Lemma 3.

Call allowances are the same in the on-net/off-net contract as under complete information. This is an incidence of the classical "no-distortion-at-the-top" result. The network operator extracts informational rent by reducing the non-discriminatory call allowance and subscription fee below $\left\{x^{*}, T^{*}\right\}$ if the informed consumer has a large personal network or a low marginal 
utility of income $\left(\theta z^{\prime}>1-\theta\right)$. The disutility $-\theta \lambda u^{\prime}$ to the informed consumer of a smaller call allowance outweighs the benefit $(1-\theta) \lambda u^{\prime} / z^{\prime}$ of a lower subscription fee and allows the operator to profitably increase the on-net/off-net subscription fee, $\widehat{T}$, with only a second-order effect on profit in the uninformed segment. In the opposite case of the informed consumer having a comparatively small personal network or a high marginal utility of income $\left(\theta z^{\prime}<1-\theta\right)$, the operator instead extracts informational rent by distorting the non-discriminatory call allowance above the first-best level, $x^{*}$. Transfers are simply redistributed between the two consumer types without generating any rent extraction in the special case of $\theta z^{\prime}=1-\theta$. The equilibrium call allowance then remains at its first-best level even if the IC constraint is binding $(\Phi>0)$; see Dessein (2003) and references therein for similar results.

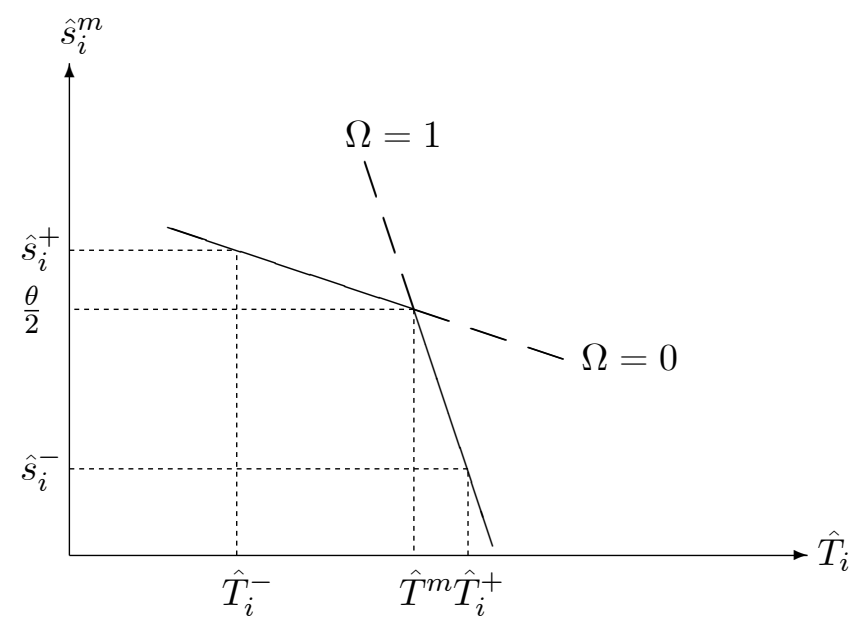

Figure 1: Kinked subscription demand

Binding incentive constraints lead to a kinked subscription demand in the informed segment, as illustrated in Figure 1. The horizontal axis displays the on-net/off-net fee, $\widehat{T}_{i}$, of network $i$, while subscription demand, $\widehat{s}_{i}^{m}$, is on the vertical axis. Let the termination rate exceed marginal termination cost, so that $q^{*}>\widehat{q}^{*}$. A small increase in $i$ 's subscription fee from $\widehat{T}^{m}$ to $\widehat{T}_{i}^{+}$ causes subscribers to move to the competitor. The change in relative network size imposes a negative network externality in $i$ and a positive network externality in $j$. This double network externality amplifies the net value of subscribing to the competing network and, by the network multiplier, leads to an accentuated drop in network $i$ 's subscriptions from $\theta / 2$ to $\widehat{s}_{i}$. Consider now the opposite case of a reduction in $\widehat{T}^{m}$ to $\widehat{T}_{i}^{-}$. The lower fee allows $i$ to attract consumers, thus creating a positive network externality in $i$. But $j$ 's on-net/off-net contract is incentive incompatible at $i$ 's lower subscription fee $\left(\widehat{v}_{j}<\theta u\left(x^{m}\right)-T^{m}\right)$, so the value of subscribing to network $j$ is determined by the non-discriminatory contract and therefore independent of network size. Hence, a reduction in $i$ 's subscription fee to $\widehat{T}_{i}^{-}$does not create any negative network externality in network $j$ for $i$ to exploit. Because the network multiplier is much smaller in this direction, $i$ 's network only increases to $\widehat{s}_{i}^{+}$.

Kinked subscription demand implies that the subscription elasticity in the informed segment is undefined at equilibrium. Instead, a continuum of pseudo-elasticities bounded by the 
directional elasticities are consistent with profit maximization:

$$
-\left.\frac{\partial \widehat{s}_{i}^{m}}{\partial \widehat{T}_{i}} \frac{1}{\widehat{s}_{i}^{m}}\right|_{\varpi_{1}=\varpi_{2}=\varpi^{m}}=\frac{2 \sigma}{1-(1+\Omega) \theta \sigma \lambda\left(u\left(q^{*}\right)-u\left(\widehat{q}^{*}\right)\right)}, \Omega \in[0,1] .
$$

Binding IC constraints thus yield a continuum of symmetric retail equilibria $\Omega \in[0,1]$. The correction term $(1-\Omega) \kappa \frac{\theta \lambda}{2}\left(u\left(q^{*}\right)-u\left(\widehat{q}^{*}\right)\right)$ in the two equilibrium fees (19) measures the impact of asymmetric information on the intensity of network competition. It is zero in the benchmark case because then $\Omega=1$.

Network operators tend to reduce the on-net/off-net subscription fee and increase the nondiscriminatory subscription fee as compared to the case of complete information to restore incentive compatibility.

$$
\kappa=\left.\frac{\frac{\partial \hat{s}_{i}^{m}}{\partial \widehat{T}_{i}} \frac{\partial \widehat{T}_{i}}{\partial T_{i}}}{\frac{\partial \widehat{s}_{i}^{m}}{\partial \widehat{T}_{i}} \frac{\partial \widehat{T}_{i}}{\partial T_{i}}+\frac{\partial s_{i}}{\partial T_{i}}}\right|_{\varpi_{1}=\varpi_{2}=\varpi^{m}}=\frac{\frac{\theta}{1-\Omega \theta \sigma \lambda\left(u\left(q^{*}\right)-u\left(\widehat{q}^{*}\right)\right)}}{\frac{\theta}{1-\Omega \theta \sigma \lambda\left(u\left(q^{*}\right)-u\left(\widehat{q}^{*}\right)\right)}+(1-\theta) z^{\prime}\left(I-T^{m}\right)}
$$

is the pass-through rate (Weyl and Fabinger, 2013) to the non-discriminatory subscription fee of the incentive correction $\Phi$. Pass-through depends on the relative sizes of the two market segments and the relative subscription elasticities. If, for example, the share of informed consumers is large ( $\theta$ is large), and subscription demand is relatively inelastic in the uninformed segment ( $z^{\prime}$ is small), a small reduction in the on-net/off-net fee generates a large inflow of informed consumers, while a large increase in the non-discriminatory fee only propagates a small loss of uninformed consumers. The pass-through rate is high in this case, and uninformed consumers have to bear most of the burden of the incentive correction through a higher non-discriminatory subscription fee. The opposite is true if the subscription elasticity is small in the informed segment, for example due to weak network externalities. Most of the incentive correction then benefits informed consumers through a lower on-net/off-net subscription fee.

In spite of the multiplicity of equilibria, selection among them according to pay-off dominance is straightforward. Competition for subscribers in the segment of informed consumers is weaker when the pseudo-elasticity (20) is smaller. If the termination markup is positive, the network multiplier, and therefore the pseudo-elasticity, is minimized for $\Omega=0$. If the termination rate is below termination cost, the pseudo-elasticity is instead minimized and network profit maximized for $\Omega=1$. The implications for the equilibrium contracts of changes in termination rates and income are the same as in the previous sections:

Lemma 5 For every termination rate $a \neq c_{T}$ with multiple equilibria, the unique pay-off dominant retail contract $\varpi^{d}=\left\{\left(q^{*}, \widehat{q}^{*}, \widehat{T}^{d}\right) ;\left(x^{d}, T^{d}\right)\right\}$ is characterized by $\Omega^{d}=0$ if a $>c_{T}$ and $\Omega^{d}=1$ if $a<c_{T}$ in Lemma 4. The non-discriminatory call allowance and subscription fee are strictly decreasing in the termination rate and weakly increasing in income for all termination rates above cost at pay-off dominant equilibrium $\left(x_{a}^{d}<0, T_{a}^{d}<0, x_{I}^{d} \geq 0\right.$ and $1>T_{I}^{d} \geq 0$ if 
$\left.a \geq c_{T}\right)^{23}$

Proof: The proof of pay-off dominance is found in Tangerås (2014) and the comparative statics results are found in the Appendix.

Unregulated termination rates Assume that network operators coordinate on the pay-off dominant equilibrium and negotiate the termination rate $a$ to maximize expected industry profit

$$
\pi^{d}=\theta\left(\widehat{T}^{d}-f-\frac{\theta \lambda}{2} c\left(q^{*}+\widehat{q}^{*}\right)\right)+(1-\theta)\left(T^{d}-f-c(1-\theta) \lambda x^{d}\right) .
$$

Substitute in the equilibrium subscription fees from Lemma 4 to get:

$$
\begin{aligned}
\pi^{d} & =\underbrace{\theta \frac{1-2 \sigma \theta \lambda\left(u\left(q^{*}\right)-u\left(\widehat{q}^{*}\right)\right)}{2 \sigma}+\frac{1-\theta}{2 \sigma z^{\prime}\left(I-T^{d}\right)}}_{\text {Average subscription elasticity }}+\underbrace{\frac{\theta^{2} \lambda}{2} c\left(q^{*}-\widehat{q}^{*}\right)}_{\text {Composition effect }} \\
+ & \underbrace{\left(1-\Omega^{d}\right) \kappa^{d} \frac{\theta \lambda}{2}\left(u\left(q^{*}\right)-u\left(\widehat{q}^{*}\right)\right)}_{\text {Network multiplier }}-\underbrace{\left(\theta-\kappa^{d}\right) \Phi\left(x^{d}, T^{d}\right)}_{\text {Incentive correction }}
\end{aligned}
$$

The subscription elasticity and the composition effect in the first row are qualitatively the same as in the previous sections; see network profits (6) and (14). The two terms on the second row are new. The first identifies the effect of incentive constraints on the network multiplier. Second-degree price competition softens network competition and drives up industry profit by reducing network externalities at the pay-off dominant equilibrium.

The second term identifies the effect of the incentive correction, $\Phi$, on industry profit. Network operators suffer a loss from incomplete information because they are forced to leave an informational rent to the informed consumers by reducing the on-net/off-net subscription fee. But the incentive correction tends to drive up the non-discriminatory subscription fee. The industry benefits from the incentive correction if the pass-through rate to the non-discriminatory subscription fee is high enough to outweigh the cost of informational rent: $\theta<\kappa^{d}=\frac{\theta}{\theta+(1-\theta) z^{\prime}\left(I-T^{d}\right)}$.

Despite its potentially positive effect on industry profit, second-degree price discrimination alone does not alter the basic insight of the workhorse model that termination rates above cost are unprofitable under termination-based discrimination. Assume that marginal utility of income is constant and equal to unity for both consumer groups, i.e. $z(y)=y$, so that the income effects are zero. The incentive correction vanishes from network profit (22) for all termination rates above cost. This is obviously the case if IC constraints are non-binding because then $\Phi=0$. If the IC constraint (15) is strictly binding, then the pass-through rate is exactly equal to the threshold $\left(\kappa^{d}=\theta\right)$ in the special case of $z^{\prime}(y)=1$. Network profit thus equals:

$$
\pi^{d}=\frac{\theta\left[1-\theta \sigma \lambda\left(1+\Omega^{d}\right)\left(u\left(q^{*}\right)-u\left(\widehat{q}^{*}\right)\right)\right]}{2 \sigma}+\frac{1-\theta}{2 \sigma}+\frac{\theta^{2} \lambda}{2} c\left(q^{*}-\widehat{q}^{*}\right) .
$$

\footnotetext{
${ }^{23}$ Let $\Omega^{d}=1$ if the equilibrium is unique. Notice also that the retail equilibrium is independent of $\Omega$ at $a=c_{T}$ because then $q^{*}=\widehat{q}^{*}$ and all network externalities vanish. To maintain consistent notation, let $x^{d}\left(c_{T}\right)=x^{m}\left(c_{T}\right)$, $T^{d}\left(c_{T}\right)=T^{m}\left(c_{T}\right)$ and $\widehat{T}^{d}\left(c_{T}\right)=\widehat{T}^{m}\left(c_{T}\right)$.
} 
Second-degree price discrimination softens network competition by reducing the importance of network externalities. But this is not enough to push unregulated termination rates above cost. The marginal network effect still dominates the marginal composition effect for termination rates above cost:

$$
\pi_{a}^{d}=\frac{\theta^{2} \lambda}{2}\left(\Omega^{d}\left(c_{O}+a\right)+a-c_{T}\right) \widehat{q}_{a}^{*}<0 .
$$

Proposition 5 Unregulated network operators maximize industry profit under second-degree price discrimination by agreeing on a termination rate at or below marginal termination cost if marginal utility of income is constant and the same for all consumers (as in A-LRT).

Proof: If $z(y)=y$, then $\pi^{d}\left(c_{T}\right)=1 / 4 \sigma$, as is easily verified. Hence,

$$
\pi^{d}\left(c_{T}\right)-\pi^{d}=\frac{\theta^{2} \lambda}{2}\left\{\Omega^{d}\left(u\left(q^{*}\right)-u\left(\widehat{q}^{*}\right)\right)+u\left(q^{*}\right)-c q^{*}-u\left(\widehat{q}^{*}\right)+c \widehat{q}^{*}\right\}>0
$$

for all $a>c_{T}$ because $q^{*}>\widehat{q}^{*}$, and $q^{*}$ is the unique maximizer of $u(q)-c q$.

I now introduce additional heterogeneity by allowing marginal utility of income to differ across the two groups of consumers. The utility of consuming the numeraire good now equals $z(y)$ for uninformed consumers. The effect on network profit of a marginal increase in the termination rate above the marginal cost of termination

$$
\begin{aligned}
& \pi_{a}^{d}=\frac{\theta^{2} \lambda}{2}\left(\Omega^{d}\left(c_{O}+a\right)+a-c_{T}\right) \widehat{q}_{a}^{*} \\
& +\underbrace{\left[\frac{1-\kappa^{d}+\Omega^{d}\left(\kappa^{d}-\theta\right)}{2 \sigma z^{\prime}\left(I-T^{d}\right)^{2}}+\frac{\theta(1-\theta)\left[\left(1-\Omega^{d}\right) \theta \lambda\left(u\left(q^{*}\right)-u\left(\widehat{q}^{*}\right)\right)+2 \Phi\left(x^{d}, T^{d}\right)\right]}{2\left(\theta+(1-\theta) z^{\prime}\left(I-T^{d}\right)\right)^{2}}\right] z^{\prime \prime}\left(I-T^{d}\right) T_{a}^{d}}_{\text {Marginal income effect }(+/ 0)} \\
& -\underbrace{\left(1-\Omega^{d}\right) \lambda\left(\theta-\kappa^{d}\right)\left(\theta u^{\prime}\left(x^{d}\right)-c(1-\theta)\right) x_{a}^{d}}_{\text {Marginal surplus extraction }(+/-)}
\end{aligned}
$$

differs from marginal profit (23) in two respects. The term on the second line of (24) is the marginal income effect. It is complicated by the fact that a marginal change in the subscription fee, $T_{a}^{d}<0$, does not only affect the subscription elasticity of the uninformed consumers, but also the incentive effect on the network multiplier, the pass-through rate and the incentive correction in (22). Still, the marginal income effect is positive under second-degree price discrimination if and only if $z^{\prime \prime}\left(I-T^{d}\right)<0$.

The term on the third line is marginal surplus extraction associated with a reduction in the non-discriminatory call allowance. Marginal surplus extraction can be positive or negative depending on the marginal effect on the incentive correction of changes in the call allowance and the magnitude of the pass-through rate.

Consider first the incentive correction, $\Phi$. A smaller call allowance makes it less attractive for informed consumers to deviate to the non-discriminatory contract. This reduces $\Phi$ by $\theta \lambda u^{\prime}\left(x^{d}\right)$. But an indirect effect works in the opposite direction. A smaller call allowance reduces user cost and therefore the subscription fee, $T^{d}$, which raises the value of the non-discriminatory contract. 
This increases $\Phi$ by $c \lambda(1-\theta)$. The direct effect dominates the indirect effect if the share of informed consumers is large enough. A higher termination rate then reduces the incentive correction through a smaller call allowance: $\left(\partial \Phi / \partial x^{d}\right) x_{a}^{d}<0$.

How changes in the incentive correction translate into surplus extraction depends on the magnitude of the pass-through rate. If the pass-through rate is below the threshold, $\theta$, network operators can extract consumer surplus by reducing the incentive correction because a smaller $\Phi$ mostly translates into a higher on-net/off-net fee, $\widehat{T}^{d}$. But if the pass-through rate is above the threshold, then networks can extract consumer surplus by increasing the incentive correction since a higher $\Phi$ for the large part drives up the non-discriminatory fee, $T^{d}$. The pass-through rate is below the threshold at a termination rate equal to marginal cost if an only if

$$
\frac{\theta-\kappa^{d}}{\theta(1-\theta)}=\frac{z^{\prime}\left(I-T^{d}\left(c_{T}\right)\right)-1}{\theta+(1-\theta) z^{\prime}\left(I-T^{d}\left(c_{T}\right)\right)}=\frac{\left.\left(\frac{1}{\partial s_{i}} \frac{\partial s_{i}}{\partial T_{i}}-\frac{1}{\widehat{s}_{i}^{m}} \frac{\partial \widehat{s}_{i}^{m}}{\partial \widehat{T}_{i}}\right)\right|_{\varpi_{1}=\varpi_{2}=\varpi^{d}\left(c_{T}\right)}}{2 \sigma\left(\theta+(1-\theta) z^{\prime}\left(I-T^{d}\left(c_{T}\right)\right)\right.}
$$

is strictly positive. This is equivalent to the semi-elasticity of subscription demand being higher for uninformed than informed consumers. Note also that this condition is independent of the sizes of the two groups and the degree of network differentiation.

The profitability of increasing the termination rate above marginal termination cost is determined by the sum of the marginal income effect and marginal surplus extraction when the IC constraint (15) is binding. If the share of informed consumers is large enough that $\partial \Phi / \partial x^{d}>0$ and the subscription demand of uninformed consumers is sufficiently elastic that $\kappa^{d}<\theta$, then marginal surplus extraction alone is enough to drive the unregulated termination rate above termination cost. But network operators can still profit from negotiating a termination rate above cost even if the pass-through rate is above the threshold, so that networks extract consumer surplus by setting the termination rate below cost. This happens if the marginal income effect is positive and strong enough. Proposition 6 summarizes the main results of this section:

Proposition 6 Assume that the benchmark contracts are incentive incompatible when termination is priced at marginal cost. Assume also that the share of informed consumers is relatively large $\left(\theta>\frac{1}{1+z^{\prime}\left(I-T^{*}\left(c_{T}\right)\right)}\right)$. Network operators profit from increasing the termination rate above marginal termination cost $\left(\pi^{d}\left(a^{d}\right)>\pi^{d}\left(c_{T}\right)\right.$ for some $\left.a^{d}>c_{T}\right)$

1. for any positive marginal income effect $\left(z^{\prime \prime}\left(I-T^{d}\left(c_{T}\right)\right)<0\right)$ if the subscription demand of uninformed consumers is sufficiently elastic relative to that of informed consumers ( $z^{\prime}(I-$ $\left.T^{*}\left(c_{T}\right)\right) \geq 1$ or not too far below unity);

2. for zero marginal income effects $(z(y)=\beta y)$ if and only if the subscription demand of uninformed consumers is more elastic than that of informed consumers $(\beta>1)$.

Proof: In the Appendix. 
The on-net/off-net contract features larger call allowances and is more expensive than the nondiscriminatory contract for termination rates above cost. ${ }^{24}$ Network operators thus profit from increasing the termination rate above cost if consumers who select the most expensive contract are those with the smallest marginal utility of income. If marginal utility of income is falling, Proposition 6 implies that operators can profitably increase termination rates above cost under the plausible assumption that high income consumers select the expensive on-net/off-net contract while low income consumers opt for the cheaper non-discriminatory contract. ${ }^{25}$

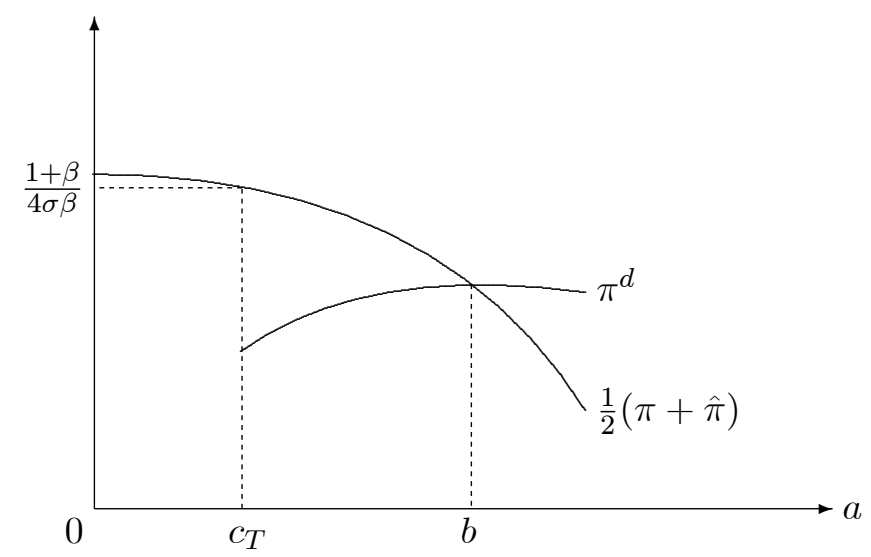

Figure 2: Network profit comparison

Contrary to non-discriminatory retail contracts, termination-based discrimination and thirddegree price discrimination, operators can profit from negotiating a termination rate above cost under second-degree price discrimination even if marginal income effects are zero for all consumers. Figure 2 illustrates the fundamental role played by incomplete information by comparing network profit $\pi^{d}$ under second-degree price discrimination with network profit $(\pi+\widehat{\pi}) / 2$ under third-degree price discrimination, assuming that the two consumer groups are equally large and that $\beta>1$. Under the assumption that $c_{O}=c_{T}$, the profit maximizing termination rate is zero under third-degree price discrimination, and network profit is monotonically decreasing for all positive termination rates; see (16). The incentive correction causes network profit to shift downwards when termination is priced at marginal cost: $\pi^{d}\left(c_{T}\right)<\left(\pi\left(c_{T}\right)+\widehat{\pi}\left(c_{T}\right)\right) / 2$. But second-degree price discrimination also reduces the network multiplier, which rotates network profit $\pi^{d}$ counter-clockwise for termination rates above cost. Softer network competition and marginal surplus extraction are enough to tilt network profit around. The benefits of softer network competition dominate the cost of the incentive correction for termination rates above $b$. The industry thus profits from incomplete information about consumer preferences for high enough termination rates in this example.

\footnotetext{
${ }^{24} q^{*}>\widehat{q}^{*}$ because $q^{*}=\widehat{q}^{*}\left(c_{T}\right)$ and $\widehat{q}_{a}^{*}<0$, while $\widehat{q}^{*} \geq x^{d}$ follows from the monotonicity condition $\left(a-c_{T}\right)\left(\widehat{q}^{*}-\right.$ $\left.x^{d}\right) \geq 0$. Incentive compatibility implies $\widehat{T}^{d}-T^{d}=\frac{\theta \lambda}{2}\left(u\left(q^{*}\right)+u\left(\widehat{q}^{*}\right)-2 u\left(x^{d}\right)\right)>0$.

${ }^{25}$ Income effects arise at the aggregate level even if individual demand is insensitive to small changes in income $\left(z^{\prime \prime}=0\right)$, provided demand varies between consumers $(\beta \neq 1)$ as a function of income differences.
} 
Proposition 6 contains statements about the profitability of deviating to a termination rate above cost, but not below cost. There are two reasons why networks would choose not to set termination rates below cost under second-degree price discrimination. First, termination rates below cost are contained in $\left[-c_{O}, c_{T}\right)$ to prevent arbitrage. Technological development has pushed marginal costs down towards zero, so the potential for setting termination rates below cost is now limited. ${ }^{26}$ But the potential for deviating to a termination rate above cost is unconstrained by arbitrage. Hence, $\pi^{d}\left(a^{d}\right)>\pi^{d}\left(c_{T}\right) \approx \pi^{d}(a)$ for all $a \in\left[-c_{O}, c_{T}\right)$ if marginal call cost, $c$, is small enough and the appropriate assumptions of Proposition 6 are met.

Second, retail equilibria might fail to exist for termination rates below cost. If the share of informed consumers is high enough, then profit maximization calls for a downward distortion of the call allowance $x^{d}$. The downward distortion, combined with the perceived marginal cost of non-discriminatory calls being higher than that of off-net calls for all $a<c_{T}$, implies $x^{d}<\widehat{q}^{*}$. But then each network can achieve a discrete increase in termination profit if $a<c_{T}$ by an infinitesimal deviation which renders the on-net/off-net contract of the competing network strictly incentive incompatible.

Social welfare Expected welfare equals

$$
w^{d}=\theta\left[\frac{\theta \lambda}{2}\left(u\left(q^{*}\right)+u\left(\widehat{q}^{*}\right)\right)-\widehat{T}^{d}\right]+(1-\theta)\left[(1-\theta) \lambda u\left(x^{d}\right)+z\left(I-T^{d}\right)\right]+\pi^{d}
$$

under second-degree price discrimination, assuming that the networks coordinate on the pay-off dominant retail equilibrium. As in the previous sections, a termination rate above cost tends to distort call allowances and redistributes income between networks and consumers. These are the two terms in the first row below:

$$
\begin{aligned}
w_{a}^{d}= & \left(\theta^{2} \widehat{q}_{a}^{*}+(1-\theta)^{2} z^{\prime}\left(I-T^{d}\right) x_{a}^{d}\right) \frac{\lambda}{2}\left(a-c_{T}\right)-(1-\theta)\left(z^{\prime}\left(I-T^{d}\right)-1\right)\left(T_{a}^{d}-c(1-\theta) \lambda x_{a}^{d}\right) \\
& +z^{\prime}\left(I-T^{d}\right)(1-\theta)^{2} \lambda\left[\frac{u^{\prime}\left(x^{d}\right)}{z^{\prime}\left(I-T^{d}\right)}-c-\frac{1}{2}\left(a-c_{T}\right)\right] x_{a}^{d} .
\end{aligned}
$$

Marginal cost pricing of termination is typically suboptimal under second-degree price discrimination even if redistribution is of no concern, i.e. when $z(y)=y$, because network operators distort the call allowance $x^{d}$ to extract rent from informed consumers even at a termination rate equal to marginal cost. This is the term on the second row in marginal welfare above. For example, network operators distort call allowances downwards if a large enough share of subscribers are informed consumers. In this case, it would be socially optimal to reduce the termination rate below cost to increase call allowances and off-set distortions. The failure to fully internalize the distortions to call allowances implies that the unregulated termination rate is distorted:

\footnotetext{
${ }^{26}$ Jullien et al. (2013), for example, estimate the sum of call origination and call termination at 2 Eurocents per minute in their calibration of the French market for mobile telephony. T-Mobile's on-net/off-net contract in the German market, "Complete Comfort", currently features free on-net calls (www.t-mobile.de/ December 8, 2013). This implies $c=0$ if calls are priced at perceived marginal cost.
} 
Proposition 7 Any profit maximizing termination rate above marginal termination cost is excessive from a welfare viewpoint under the assumptions of Proposition 6 if redistribution to network operators is not too favourable (if $z^{\prime}\left(I-T^{*}\left(c_{T}\right)\right) \geq 1$ or not too far below unity).

Proof: In the Appendix.

A numerical example To assess the practical relevance of second-degree price discrimination and Propositions 6 and 7, recall the example of the Swedish mobile operator Tele2 in the introduction. Tele2 offers two main contracts, the on-net/off-net contract "Kompis" and the non-discriminatory contract "Smart". The price of a two minute on-net call is $p^{*}=0.99$ Swedish kronor (SEK) in "Kompis" while a call of the same length to the other domestic networks costs $\widehat{p}^{*}=2.37$ SEK. The price of a two minute call in "Smart" to all domestic networks is $r^{d}=2.37$ SEK (www.tele2.se, December 5, 2013). ${ }^{27}$

According to the present model, on-net and off-net calls should be priced at perceived marginal cost in "Kompis" independently of the mode of competition: $p^{*}=c$ and $\widehat{p}^{*}=c_{O}+a$. An undistorted price in "Smart" would be a weighted average of the "Kompis" prices, $r^{*}=$ $s p^{*}+(1-s) \widehat{p}^{*}$, where $s$ is the market share of Tele2. The observed "Smart" price is upwards distorted from this perspective: $r^{d}-r^{*}=s\left(\widehat{p}^{*}-p^{*}\right)>0$. As a consequence, call volumes are downward distorted in "Smart", $x^{d}<x^{*}$, because call demand is decreasing in price.

The observed pricing policy is consistent with Tele2 reducing call volumes in the nondiscriminatory contract "Smart" with the purpose of increasing the subscription fee of the onnet/off-net contract "Kompis". Returning to Lemma 4, call volumes are downward distorted if and only if $\theta>\left(1+z^{\prime}\left(I-T^{d}\right)\right)^{-1}$. Hence, the observed prices are consistent with the underlying assumptions of Proposition 6. It is then sufficient that enough high income consumers prefer the "Kompis" contract to generate the observed termination rates above cost: $a-c_{T}=\widehat{p}^{*}-p^{*}=1.38$.

Discussion The main mechanism which softens network competition under second-degree price discrimination is the binding IC constraint on the on-net/off-net contract which eliminates the negative network externality in the competing network and leads to a kinked subscription demand. This mechanism should arise in any model in which IC constraints interact with network externalities and is therefore not particular to this specific model.

The assumption that only consumers of the same type call each other simplifies the analysis, but is not restrictive. Tangerås (2014) considers an alternative setup in which all consumers call each other. Under a type independent call pattern, network externalities also depend on the properties of the non-discriminatory contract because the value of the on-net/off-net contract is now a function of $i$ 's entire network, $\widehat{s}_{i}^{m}+s_{i}$. Further, marginal termination profit is non-zero even at symmetric market shares. These two effects render the characterization of equilibrium retail contracts more complicated than in Lemma 4 and in particular complicate the second-order conditions. Second-degree price discrimination still softens network competition by reducing the

\footnotetext{
${ }^{27}$ Interestingly, $r^{d}=\widehat{p}^{*}$ implies that "Kompis" and "Smart" satisfy the monotonicity constraint $\left(a-c_{T}\right)\left(\widehat{q}^{*}-\right.$ $\left.x^{d}\right) \geq 0$ of Lemma 4 for all termination rates above cost.
} 
magnitude of network externalities, and an incentive correction arises which reduces industry profit if and only if the pass-through rate is below the threshold, $\theta$. Insights regarding network operators' choice of termination rates are similar to the present model. For example, it is profitable to raise the termination rate above marginal termination cost for any positive marginal income effect if informed and uninformed consumers have similar subscription elasticities at termination rates equal to marginal cost.

\section{Conclusion}

A main concern with network competition is the termination rates operators charge for connecting calls from each other. The perception is that unregulated networks can use termination rates to distort competition. Therefore, termination rates are usually regulated. Yet, authorities tend to view telecoms regulation as temporary, at least in Europe: "As normal market conditions develop, regulation can be rolled back, and competition law, as applied to industry in general, will replace sector-specific intervention" (European Commission, 2007). A relevant question is whether markets now have developed so far that deregulation is viable.

Most of the literature on network competition concludes that unregulated operators either are indifferent or would negotiate termination rates below marginal termination cost. As technological development has pushed marginal costs down towards zero, the potential for setting termination rates below cost now is limited. These developments would seem to favour deregulation. Yet, there are circumstances under which operators would instead prefer termination rates above cost; for example, if market coverage is incomplete and total subscription demand elastic (Jullien et al., 2013), or if fixed-to-mobile termination represents a substantial source of income to mobile operators (Armstrong and Wright, 2009). Market coverage now exceeds 100 percent in most OECD countries in terms of mobile subscriptions per capita. Mobile telephony is gaining rapidly in importance relative to fixed telephony: In the US, for example, the mobileonly population went from 6.1 percent in 2004 to 22.7 percent in 2009 (all statistics are from OECD, 2011). As the incentive for networks to negotiate excessive termination rates is correspondingly weak in fully covered markets dominated by mobile telephony, these trends point to an increased scope for deregulation. However, there are other reasons why operators would prefer termination rates above cost.

This paper analyses the role of income effects in demand. I show that weak income effects are enough to drive unregulated termination rates above cost if networks compete in nondiscriminatory contracts. This holds even under termination-based discrimination if networks are differentiated. Operators profit from increasing termination rates above cost under seconddegree price discrimination if a sufficient share of consumers prefer on-net/off-net contracts and their subscription demand is relatively inelastic. Income effects are inherent to consumer preferences and are likely to persist independently of market developments on the supply side. Deregulation could therefore lead to a jump in termination rates and corresponding welfare losses even in mature telecoms markets. 


\section{Appendix}

\section{Proof of Proposition 2}

Substitute (7) into (8) and use (5) to obtain

$$
w_{a}=\frac{(1-\theta) \lambda \Psi}{4 \sigma z^{\prime}}\left[\Gamma(a) z^{\prime \prime}+\left(c_{T}-a\right) \sigma\left(z^{\prime}\right)^{3}\right]
$$

after simplifications, where $\Gamma(a)=\left(c+\frac{a-c_{T}}{2}\right) z^{\prime}\left(I-T^{*}(a)\right)-c$.

If $z^{\prime}\left(I-T^{*}\left(c_{T}\right)\right) \geq 1$, then $\Gamma\left(c_{T}\right)=c z^{\prime}\left(I-T^{*}\left(c_{T}\right)\right)-c \geq 0$. In this case, $\Gamma(a)>0$ for all $a>c_{T}$ because

$$
\Gamma_{a}=\frac{1}{2} z^{\prime}-\left(c+\frac{a-c_{T}}{2}\right) z^{\prime \prime} T_{a}^{*}=\frac{\Psi u^{\prime \prime}}{4 \sigma z^{\prime}}\left(z^{\prime \prime}-2 \sigma\left(z^{\prime}\right)^{2}\right)>0,
$$

where I have substituted in $T_{a}^{*}$ from (5) and simplified. Thus, $w_{a}<0$ for all $a>c_{T}$ because then $\Gamma(a) z^{\prime \prime} \leq 0$ and $\left(c_{T}-a\right) \sigma\left(z^{\prime}\right)^{3}<0$. Hence, $a^{o p t} \in\left[-c_{O}, c_{T}\right]$.

If $z^{\prime}\left(I-T^{*}\left(c_{T}\right)\right)<1$, then $\Gamma\left(c_{T}\right)<0$. Note also that $\Gamma(a) \geq\left(c+\frac{a-c_{T}}{2}\right) z^{\prime}(I)-c$ because $z^{\prime \prime} \leq 0$. Thus, $\Gamma(a)>0$ for $a$ large enough. Hence, there exists a unique $\bar{a}>c_{T}$ satisfying $\Gamma(\bar{a})=0 . \quad w_{a}<0$ for all $a>\bar{a}>c_{T}$ because then $\Gamma(a) z^{\prime \prime} \leq 0$ and $\left(c_{T}-a\right) \sigma\left(z^{\prime}\right)^{3}<0$. Moreover, $w_{a}>0$ for all $a<c_{T}<\bar{a}$ because then $\Gamma(a) z^{\prime \prime} \geq 0$ and $\left(c_{T}-a\right) \sigma\left(z^{\prime}\right)^{3}>0$. Hence, $z^{\prime}\left(I-T^{*}\left(c_{T}\right)\right)<1$ implies that $a^{o p t} \in\left[c_{T}, \bar{a}\right]$.

\section{Proof of Proposition 4}

Define consumer surplus $\widehat{v}(a)=\frac{\theta \lambda}{2}\left(u\left(q^{*}\right)+u\left(\widehat{q}^{*}\right)\right)+z\left(I-\widehat{T}^{*}\right)$. The marginal effect on consumer surplus of an increase in the termination rate is

$$
\begin{aligned}
\widehat{v}_{a} & =z^{\prime}\left[\frac{\theta \lambda}{2} c q_{a}^{*}+\frac{\theta \lambda}{2}\left(c_{O}+a\right) \widehat{q}_{a}^{*}-\widehat{T}_{a}^{*}\right] \\
& =-\widehat{\Psi} \frac{\theta \lambda}{2 \sigma}\left(c_{O}+a\right)\left(z^{\prime}\right)^{2}\left[\sigma u^{\prime \prime}+\psi u^{\prime \prime} z^{\prime \prime}+\theta \sigma \lambda c^{2} z^{\prime \prime}\right]
\end{aligned}
$$

where in the second row I have substituted in (13) and simplified.

If the income effect is weak enough $\left(z^{\prime \prime} \lesssim 0\right)$, then $\widehat{v}_{a}>0$ for all $a>-c_{O}$. In this case,

$$
\widehat{w}\left(\widehat{a}^{*}\right)-\widehat{w}(a)=\widehat{v}\left(\widehat{a}^{*}\right)-\widehat{v}(a)+\widehat{\pi}\left(\widehat{a}^{*}\right)-\widehat{\pi}(a)>0
$$

for all $-c_{O} \leq a<\widehat{a}^{*}<c_{T}$ by monotonicity $\left(\widehat{v}_{a}>0\right)$ and revealed preference $\left(\widehat{\pi}\left(\widehat{a}^{*}\right) \geq \widehat{\pi}(a)\right)$. Hence, $a^{o p t} \geq \widehat{a}^{*}$. The inequality is strict because $\widehat{w}_{a}\left(\widehat{a}^{*}\right)=\widehat{v}_{a}\left(\widehat{a}^{*}\right)+\widehat{\pi}_{a}\left(\widehat{a}^{*}\right)=\widehat{v}_{a}\left(\widehat{a}^{*}\right)>0$.

For any positive income effect $\left(z^{\prime \prime}<0\right)$ and if the degree of network differentiation $(\sigma)$ is small enough, then $\widehat{v}_{a}<0$ for all $a>-c_{O}$. In this case, $\widehat{w}\left(\widehat{a}^{*}\right)>\widehat{w}(a)$ for all $a>\widehat{a}^{*}>c_{T}$ 
again by monotonicity $\left(\widehat{v}_{a}<0\right)$ and revealed preference $\left(\widehat{\pi}\left(\widehat{a}^{*}\right) \geq \widehat{\pi}(a)\right)$. Hence, $a^{\text {opt }} \leq \widehat{a}^{*}$. The inequality is strict because $\widehat{w}_{a}\left(\widehat{a}^{*}\right)=\widehat{v}_{a}\left(\widehat{a}^{*}\right)<0$.

\section{Proof of Lemma 3}

I first establish a sufficient condition under which $\widehat{v}(a)-\theta \lambda u\left(x^{*}(a)\right)+T^{*}(a)$ is strictly increasing in $a \in\left[-c_{O}, c_{T}\right]$. Because $\widehat{v}_{a}>0$ for all $a>-c_{O}$ if the income effect is weak enough, see the proof of Proposition 4, the required monotonicity holds if $\theta \lambda u^{\prime}\left(x^{*}\right) x_{a}^{*} \leq T_{a}^{*}$ for all $a \in\left[-c_{O}, c_{T}\right]$. By an inspection of equation (17), it is evident that the inequality holds if $\theta u^{\prime}\left(x^{*}\right) \geq c(1-\theta)$ because $x_{a}^{*}<0$, see equation (5), and $\pi_{a} \geq 0$, see Proposition 1. By utilizing the equilibrium relation $u^{\prime}\left(x^{*}\right)=\left(c+\frac{1}{2}\left(a-c_{T}\right)\right) z^{\prime}$ and rearranging terms, I obtain

$$
\theta u^{\prime}\left(x^{*}\right)-c(1-\theta)=\frac{\theta}{2}\left(c_{O}+a\right) z^{\prime}\left(I-T^{*}\right)+\frac{\theta}{2} c z^{\prime}\left(I-T^{*}\right)-c(1-\theta) .
$$

By $z^{\prime \prime} \leq 0$ and $T_{a}^{*}<0$, it follows that $z^{\prime}\left(I-T^{*}(a)\right) \geq z^{\prime}\left(I-T^{*}\left(c_{T}\right)\right)$ for all $a \in\left[-c_{O}, c_{T}\right]$. Hence, $\theta u^{\prime}\left(x^{*}\right) \geq c(1-\theta)$ for all $a \in\left[-c_{O}, c_{T}\right]$ if $\theta z^{\prime}\left(I-T^{*}\left(c_{T}\right)\right) \geq 2(1-\theta)$. This is equivalent to $\theta \geq 2\left(2+z^{\prime}\left(I-T^{*}\left(c_{T}\right)\right)\right)^{-1}$.

To complete the proof, I establish sufficient conditions under which $\widehat{v}\left(c_{T}\right)<\theta \lambda u\left(x^{*}\left(c_{T}\right)\right)-$ $T^{*}\left(c_{T}\right)$. Use $\widehat{v}\left(c_{T}\right)=\theta \lambda u\left(q^{*}\right)-\widehat{T}^{*}\left(c_{T}\right)$ and the equilibrium subscription fees (4) and (12) to get

$$
\begin{aligned}
& \widehat{v}\left(c_{T}\right)-\theta \lambda u\left(x^{*}\left(c_{T}\right)\right)+T^{*}\left(c_{T}\right) \\
= & -\theta \lambda\left[u\left(x^{*}\left(c_{T}\right)\right)-u\left(q^{*}\right)+z^{\prime}\left(I-T^{*}\left(c_{T}\right)\right) c\left(q^{*}-x^{*}\left(c_{T}\right)\right)\right]-(2 \theta-1) c \lambda x^{*}\left(c_{T}\right) \\
& -\left(z^{\prime}\left(I-T^{*}\left(c_{T}\right)\right)-1\right)\left[\frac{1-2 c \theta \sigma \lambda z^{\prime}\left(I-T^{*}\left(c_{T}\right)\right)\left(q^{*}-x^{*}\left(c_{T}\right)\right)}{2 \sigma z^{\prime}\left(I-T^{*}\left(c_{T}\right)\right)}\right]
\end{aligned}
$$

after rearranging terms. The first term on the right-hand side of the equality is zero if $z^{\prime}(I-$ $\left.T^{*}\left(c_{T}\right)\right)=1$ because then $x^{*}\left(c_{T}\right)=q^{*}$, and negative if $z^{\prime}\left(I-T^{*}\left(c_{T}\right)\right) \neq 1$ because $x^{*}\left(c_{T}\right)$ is the unique maximizer of $u(x)-z^{\prime}\left(I-T^{*}\left(c_{T}\right)\right) c x$. The second term is negative if $\theta>1 / 2$. The third term is dominated by the first two terms for $\left|z^{\prime}\left(I-T^{*}\left(c_{T}\right)\right)-1\right|$ small enough and is negative if $z^{\prime}\left(I-T^{*}\left(c_{T}\right)\right)>1$ and $c \sigma \lambda$ is small enough.

I finally show that the IC constraint (15) is satisfied for all $a \in\left[-c_{O}, c_{T}\right]$ if $\theta<1 / 2$, $z^{\prime}\left(I-T^{*}\left(c_{T}\right)\right) \leq 1$ and $c$ is small enough. The first term on the right-hand side of

$$
\begin{aligned}
& \widehat{v}\left(c_{T}\right)-\theta \lambda u\left(x^{*}\left(c_{T}\right)\right)+T^{*}\left(c_{T}\right) \\
= & \theta \lambda\left(u\left(q^{*}\right)-c q^{*}-u\left(x^{*}\left(c_{T}\right)\right)+c x^{*}\left(c_{T}\right)\right)+(1-2 \theta) c \lambda x^{*}\left(c_{T}\right)+\frac{1-z^{\prime}\left(I-T^{*}\left(c_{T}\right)\right)}{2 \sigma z^{\prime}\left(I-T^{*}\left(c_{T}\right)\right)} .
\end{aligned}
$$


is non-negative because $q^{*}$ is the unique maximizer of $u(q)-c q$, the second term is strictly positive if $\theta<1 / 2$, while the third term is non-negative if $z^{\prime}\left(I-T^{*}\left(c_{T}\right)\right) \leq 1$. By continuity, incentive compatibility extends to all $a \in\left[-c_{O}, c_{T}\right]$ if $c$ is sufficiently small.

\section{Properties of the retail contracts $\varpi^{m}$}

Monotonicity Assume that $a=c_{T}$ and rewrite the equilibrium condition (18) as

$$
\frac{u^{\prime}\left(x^{m}\right)-u^{\prime}\left(\widehat{q}^{*}\right)}{u^{\prime}\left(x^{m}\right) z^{\prime}\left(I-T^{m}\right)}=\left(\frac{\theta}{1-\theta} z^{\prime}\left(I-T^{m}\right)-1\right) \frac{2 \theta \sigma \Phi\left(x^{m}, T^{m}\right)}{\theta+(1-\theta) z^{\prime}\left(I-T^{m}\right)}+\frac{c\left(z^{\prime}\left(I-T^{m}\right)-1\right)}{u^{\prime}\left(x^{m}\right) z^{\prime}\left(I-T^{m}\right)}
$$

I show below that $T^{m}\left(c_{T}\right) \geq T^{*}\left(c_{T}\right)$. Hence, $x^{m}\left(c_{T}\right)<\widehat{q}^{*}\left(c_{T}\right)$ by concavity of $u$ and $z$ if $\theta \geq\left(z^{\prime}\left(I-T^{*}\left(c_{T}\right)\right)+1\right)^{-1}$ and $z^{\prime}\left(I-T^{*}\left(c_{T}\right)\right)$ is not too small. By continuity, $x^{m}(a)<\widehat{q}^{*}(a)$ extends to an interval $a \in\left(c_{T}, \widehat{a}\right)$. Define $x(\gamma)$ and $T(\gamma)$ by

$$
\begin{aligned}
& \frac{1}{z^{\prime}(I-T)}-2 \sigma \gamma\left(\frac{\theta}{1-\theta} z^{\prime}(I-T)-1\right)\left[T-f-c(1-\theta) \lambda x-\frac{1}{2 \sigma z^{\prime}(I-T)}\right]=\frac{c}{u^{\prime}(x)} \\
& T-f-c(1-\theta) \lambda x-\frac{1}{2 \sigma z^{\prime}}=\frac{\theta \gamma \Phi(x, T)}{\theta+(1-\theta) z^{\prime}(I-T)} .
\end{aligned}
$$

$T^{m}\left(c_{T}\right)=T(1)$ and $T^{*}\left(c_{T}\right)=T(0)$ by construction. Differentiation yields

$$
\frac{d T}{d \gamma}=D\left[2 \lambda \sigma \kappa \gamma^{2}(1-\theta)\left(1+2 \kappa \sigma z^{\prime} \Phi\right) \frac{u^{\prime}}{z^{\prime}}\left(\frac{\theta}{1-\theta} z^{\prime}-1\right)^{2}-\frac{c u^{\prime \prime}}{\left(u^{\prime}\right)^{2}}\right] \theta \Phi
$$

which is non-negative in general and strictly positive for $\Phi>0$ because

$$
\begin{aligned}
D^{-1}= & 2 \theta(1-\theta) \sigma \gamma^{2} \lambda \frac{u^{\prime}}{z^{\prime}}\left(\frac{\theta}{1-\theta} z^{\prime}-1\right)^{2}\left(1+2 \kappa \sigma z^{\prime} \Phi\right)-\left(\theta+(1-\theta) z^{\prime}\right) \frac{c u^{\prime \prime}}{\left(u^{\prime}\right)^{2}} \\
& -\left[2 \gamma \sigma \lambda\left(\frac{\gamma \theta^{3}}{1-\theta} u^{\prime}+c(1-\theta)^{2}\right)-c(1-\theta) \frac{u^{\prime \prime}}{\left(u^{\prime}\right)^{2}}+2 \sigma \gamma \lambda \theta^{2} c(1-\gamma)\right]\left(\frac{1}{2 \sigma z^{\prime}}+\kappa \gamma \Phi\right) z^{\prime \prime} \\
& -\left[2 \sigma \gamma \lambda \theta^{2} c\left(z^{\prime}\right)^{2} \kappa \gamma \Phi+\lambda \gamma \theta^{2} u^{\prime}+\lambda c \theta(1-\theta)+\lambda c(1-\theta)^{2} z^{\prime}-\frac{c \theta u^{\prime \prime}}{2 \sigma\left(u^{\prime}\right)^{2}}\right](1-\gamma) \frac{z^{\prime \prime}}{\left(z^{\prime}\right)^{2}}
\end{aligned}
$$

is strictly positive. Hence, $T^{m}\left(c_{T}\right) \geq T^{*}\left(c_{T}\right)$ with strict inequality if $\Phi\left(x^{*}\left(c_{T}\right), T^{*}\left(c_{T}\right)\right)>0$.

Incentive compatibility of the non-discriminatory contract Assume that $a>c_{T}$ and that the IC constraint of the on-net/off-net contract is strictly binding. The non-discriminatory contract is incentive compatible if

$$
z\left(I-T^{m}\right)-z\left(I-\widehat{T}^{m}\right)+(1-\theta) \lambda\left[u\left(x^{m}\right)-\frac{1}{2} u\left(q^{*}\right)-\frac{1}{2} u\left(\widehat{q}^{*}\right)\right] \geq 0
$$

because then the uninformed consumer would select the non-discriminatory contract even if she 
were informed. Substitute

$$
z\left(I-T^{m}\right)-z\left(I-\widehat{T}^{m}\right)=\int_{I-\widehat{T}^{m}}^{I-T^{m}}\left(z^{\prime}(y)-z^{\prime}\left(I-T^{m}\right)\right) d y+\left(\widehat{T}^{m}-T^{m}\right) z^{\prime}\left(I-T^{m}\right)
$$

and the binding on-net/off-net constraint

$$
\widehat{T}^{m}-T^{m}=\frac{\lambda \theta}{2}\left(u\left(q^{*}\right)-u\left(\widehat{q}^{*}\right)\right)+\theta \lambda\left(u\left(\widehat{q}^{*}\right)-u\left(x^{m}\right)\right)
$$

into (27) to get the modified non-discriminatory IC constraint

$$
\int_{I-\widehat{T}^{m}}^{I-T^{m}}\left(z^{\prime}(y)-z^{\prime}\left(I-T^{m}\right)\right) d y+\frac{1-\theta}{\theta}\left(\frac{\theta}{1-\theta} z^{\prime}\left(I-T^{m}\right)-1\right)\left(\widehat{T}^{m}-T^{m}\right) \geq 0 .
$$

$\widehat{T}^{m}>T^{m}$ from (28) because $a>c_{T}$ implies $q^{*}>\widehat{q}^{*}$, while $\widehat{q}^{*} \geq x^{m}$ by the monotonicity condition $\left(a-c_{T}\right)\left(\widehat{q}^{*}-x^{m}\right) \geq 0$. Hence, the first term on the left-hand side of (29) is nonnegative, while the second term is non-negative if $\theta z^{\prime}\left(I-T^{m}\right) \geq 1-\theta$. This inequality is satisfied for all $a \in\left[c_{T}, \widehat{a}\right]$ and for some $\widehat{a}>c_{T}$ if $\theta>\left(1+z^{\prime}\left(I-T^{*}\left(c_{T}\right)\right)^{-1}\right.$ by $T^{m}\left(c_{T}\right) \geq T^{*}\left(c_{T}\right)$ and continuity of $T^{m}$ in $a$.

Comparative statics of the pay-off dominant equilibrium By total differentiation of the equilibrium conditions (18) and (19)

$$
\begin{aligned}
x_{a}^{d} & =\frac{\Psi^{d}}{2 u^{\prime}\left(x^{d}\right)}\left[(1-\theta)\left(T^{d}-f-c(1-\theta) \lambda x^{d}\right) z^{\prime \prime}-\theta-(1-\theta) z^{\prime}\right] \\
T_{a}^{d} & =-\frac{\Psi^{d}}{2 u^{\prime}\left(x^{d}\right)} \lambda\left(\theta^{2} u^{\prime}+c(1-\theta)^{2} z^{\prime}\right)
\end{aligned}
$$

where $u^{\prime}=u^{\prime}\left(x^{d}\right), u^{\prime \prime}=u^{\prime \prime}\left(x^{d}\right)$ and

$$
\begin{aligned}
\left(\Psi^{d}\right)^{-1}= & {\left[(1-\theta)\left(c+\frac{1}{2}\left(a-c_{T}\right)\right) \frac{u^{\prime \prime}}{\left(u^{\prime}\right)^{2}}-2 \sigma \lambda\left(\frac{\theta^{3}}{1-\theta} u^{\prime}+c(1-\theta)^{2}\right)\right]\left[T^{d}-f-c(1-\theta) \lambda x^{d}\right] z^{\prime \prime} } \\
& -\left(\theta+(1-\theta) z^{\prime}\right)\left(c+\frac{1}{2}\left(a-c_{T}\right)\right) \frac{u^{\prime \prime}}{\left(u^{\prime}\right)^{2}}+2 \theta \sigma \lambda\left(\frac{\theta}{1-\theta} z^{\prime}-1\right)\left(\theta u^{\prime}-(1-\theta) c\right) .
\end{aligned}
$$

The term in the first row of $\left(\Psi^{d}\right)^{-1}$ is non-negative, the first term in the second row is strictly positive and dominates the last term for $\sigma \lambda$ small enough. $\left(\Psi^{d}\right)^{-1}>0$ also for $\left|a-c_{T}\right|$ small enough. To see this last point, rewrite the equilibrium condition (18) as

$$
\frac{\frac{\theta}{1-\theta} u^{\prime}\left(x^{d}\right)-c}{u^{\prime}\left(x^{d}\right)}=\frac{\theta\left(a-c_{T}\right)+4 \sigma c(1-\theta)\left(\frac{\theta}{1-\theta} z^{\prime}-1\right)\left(T^{d}-f-c(1-\theta) \lambda x^{d}\right)}{(1-\theta)\left(c_{O}+a+c\right)} .
$$

If $\frac{\theta}{1-\theta} z^{\prime}\left(I-T^{m}\left(c_{T}\right)\right) \neq 1$, then $\left(\frac{\theta}{1-\theta} z^{\prime}-1\right)\left(\frac{\theta}{1-\theta} u^{\prime}-c\right)>0$ and therefore $\left(\Psi^{d}\right)^{-1}>0$ for $\left|a-c_{T}\right|$ 
small enough. If $\frac{\theta}{1-\theta} z^{\prime}\left(I-T^{m}\left(c_{T}\right)\right)=1$, then the first term in the second row of $\left(\Psi^{d}\right)^{-1}$ dominates the last term for $\left|a-c_{T}\right|$ small enough.

$$
\begin{aligned}
x_{I}^{d} & =-2 \sigma \Psi^{d} \frac{\theta^{2}+(1-\theta)^{2}}{1-\theta}\left[T^{d}-f-c(1-\theta) \lambda x^{d}\right] z^{\prime \prime} \\
T_{I}^{d} & =\Psi^{d}\left[(1-\theta)\left(c+\frac{1}{2}\left(a-c_{T}\right)\right) \frac{u^{\prime \prime}}{\left(u^{\prime}\right)^{2}}-2 \sigma \lambda\left(\frac{\theta^{3}}{1-\theta} u^{\prime}+c(1-\theta)^{2}\right)\right]\left[T^{d}-f-c(1-\theta) \lambda x^{d}\right] z^{\prime \prime} \\
1-T_{I}^{d} & =-\Psi^{d}\left[\left(\theta+(1-\theta) z^{\prime}\right)\left(c+\frac{1}{2}\left(a-c_{T}\right)\right) \frac{u^{\prime \prime}}{\left(u^{\prime}\right)^{2}}+2 \theta \sigma \lambda\left(\frac{\theta}{1-\theta} z^{\prime}-1\right)\left(\theta u^{\prime}-c(1-\theta)\right)\right]
\end{aligned}
$$

imply that $x_{I}^{d}>0$ and $T_{I}^{d}>0$ if and only if $z^{\prime \prime}<(=) 0$, while $T_{I}^{d}<1$ if $\sigma \lambda$ is small enough or $\left|a-c_{T}\right|$ small enough.

\section{Proof of Proposition 6}

Substitute the equilibrium call allowance (18) into marginal profit (24) to get

$$
\begin{aligned}
\pi_{a}^{d}= & \frac{\theta^{2} \lambda}{2}\left(\widehat{q}_{a}^{*}+\frac{\theta(1-\theta)\left(1-z^{\prime}\right)}{\theta+(1-\theta) z^{\prime}} \frac{2 u^{\prime}\left(x^{d}\right)}{c_{O}+a+c} x_{a}^{d}\right)\left(a-c_{T}\right)+\left[\frac{1-\kappa^{d}}{2 \sigma\left(z^{\prime}\right)^{2}}+\frac{\theta(1-\theta)\left[\theta \lambda\left(u\left(q^{*}\right)-u\left(\widehat{q}^{*}\right)\right)+2 \Phi\right]}{2\left(\theta+(1-\theta) z^{\prime}\right)^{2}}\right] z^{\prime \prime} T_{a}^{d} \\
& -\frac{2 \lambda c \sigma \theta(1-\theta)^{3} u^{\prime}\left(x^{d}\right)}{\left(c_{O}+a+c\right)\left(\theta+(1-\theta) z^{\prime}\right)}\left(\frac{1}{\sigma(1-\theta) z^{\prime}}+\frac{\theta\left[\theta \lambda\left(u\left(q^{*}\right)-u\left(\widehat{q}^{*}\right)\right)+2 \Phi\right]}{\theta+(1-\theta) z^{\prime}}\right)\left(z^{\prime}-1\right)\left(\frac{\theta}{1-\theta} z^{\prime}-1\right) x_{a}^{d}
\end{aligned}
$$

under the assumption that $\Omega^{d}=0$. Recall that $T^{d}\left(c_{T}\right)=T^{m}\left(c_{T}\right) \geq T^{*}\left(c_{T}\right)$. Hence $\theta z^{\prime}\left(I-T^{d}\right)>$ $1-\theta$ for all $a \gtrsim c_{T}$ by the assumption that $\theta z^{\prime}\left(I-T^{*}\left(c_{T}\right)\right)>1-\theta$. If $z^{\prime \prime}\left(I-T^{d}\left(c_{T}\right)\right)<0$ and $z^{\prime}\left(I-T^{*}\left(c_{T}\right)\right) \geq 1$ or not too far below unity, then $\pi_{a}^{d}>0$ for $a \gtrsim c_{T}$ because the first term in marginal profit vanishes and the third term in marginal profit is either non-negative or dominated by the positive marginal income effect for $a \gtrsim c_{T}$.

The marginal income effect is zero if $z(y)=\beta y$. Still, $\pi_{a}^{d}>0$ for $a \gtrsim c_{T}$ if $\beta>1$ since marginal surplus extraction is strictly positive in this case. If $\beta<1$, then the first and the third term in marginal profit are negative for all $a>c_{T}$. Hence, it is unprofitable to negotiate a termination rate above cost with a strictly binding IC constraint. It is always unprofitable to negotiate a termination rate above cost with non-binding IC constraints if the marginal income effect is zero because of the strength of the marginal network effect; see Proposition 3. Hence, $\pi^{d}\left(c_{T}\right)>\pi^{d}(a)$ for all $a>c_{T}$ if $\theta>(1+\beta)^{-1}$ and $\beta<1$.

\section{Proof of Proposition 7}

Recall from the proof of Lemma 3 that a sufficient condition for $\widehat{v}-\theta \lambda u\left(x^{*}\right)+T^{*}$ to be locally increasing in $a$ is $\theta u^{\prime}\left(x^{*}\right)>c(1-\theta)$. The net benefit to the informed consumer of taking the on-net/off-net contract is strictly increasing for all $a \geq c_{T}$ if $\theta u^{\prime}\left(x^{*}\left(c_{T}\right)\right) \geq c(1-\theta)$ because $u^{\prime \prime}\left(x^{*}\right) x_{a}^{*}>0$. This condition is equivalent to $\theta z^{\prime}\left(I-T^{*}\left(c_{T}\right)\right) \geq 1-\theta$ and therefore satisfied 
by assumption. Moreover, $\Phi\left(x^{*}\left(c_{T}\right), T^{*}\left(c_{T}\right)\right)>0$. Hence there exists an $\widetilde{a}>c_{T}$ such that $\Phi\left(x^{*}, T^{*}\right)>0$ for $a \geq c_{T}$ if and only if $a<\widetilde{a}$.

The social optimum satisfies $a^{\text {opt }} \leq \widetilde{a}$ if $z^{\prime}\left(I-T^{*}\left(c_{T}\right)\right) \geq 1$ or not too far below unity. To see this, note that marginal welfare $w_{a}^{d}=\theta \widehat{w}_{a}+(1-\theta) w_{a}<0$ for all $a>\widetilde{a}$, because $\widehat{w}_{a}=\frac{\theta \lambda}{2}\left(a-c_{T}\right) \widehat{q}_{a}^{*}<0$ for all $a>c_{T}$ while $w_{a}<0$ for all $a>\bar{a}$, where $\bar{a}<\widetilde{a}$ if $z^{\prime}\left(I-T^{*}\left(c_{T}\right)\right) \geq 1$ or not too far below unity; see the proof of Proposition 2.

If $a^{d}>\widetilde{a}$, the proof is done. Assume therefore that $a^{d} \in\left(c_{T}, \widetilde{a}\right]$. Consumer net surplus at pay-off dominant equilibrium $\left(\Omega^{d}=0\right)$ equals

$$
v^{d}=\left(\theta^{2}+(1-\theta)^{2}\right) \lambda u\left(x^{d}\right)-\theta T^{d}+(1-\theta) z\left(I-T^{d}\right)
$$

in the domain $a \in\left(c_{T}, \widetilde{a}\right]$, where I have substituted in the binding IC constraint (28) and simplified. Marginal consumer net surplus equals

$$
v_{a}^{d}=\frac{\Psi^{d}(1-\theta) \lambda}{2 u^{\prime}}\left[\left(\theta^{2}+(1-\theta)^{2}\right)\left(T^{d}-f-c(1-\theta) \lambda x^{d}\right) u^{\prime} z^{\prime \prime}-\left(\theta+(1-\theta) z^{\prime}\right)(1-\theta)\left(u^{\prime}-c z^{\prime}\right)\right],
$$

after substituting in (30). It is negative if $u^{\prime}\left(x^{d}\right) \geq c z^{\prime}\left(I-T^{d}\right)$. Notice that $u^{\prime \prime}\left(x^{d}\right) x_{a}^{d}+c z^{\prime \prime} T_{a}^{d}>0$, so the inequality is satisfied for $a \geq c_{T}$ if $u^{\prime}\left(x^{d}\left(c_{T}\right)\right) \geq c z^{\prime}\left(I-T^{d}\left(c_{T}\right)\right)$. Evaluated at $a=c_{T}$, the rearranged equilibrium condition (18)

$$
\frac{u^{\prime}\left(x^{d}\right)-c z^{\prime}\left(I-T^{d}\right)}{u^{\prime}\left(x^{d}\right) z^{\prime}\left(I-T^{d}\right)}=\left(\frac{\theta}{1-\theta} z^{\prime}\left(I-T^{d}\right)-1\right) \frac{2 \theta \sigma \Phi\left(x^{d}, T^{d}\right)}{\theta+(1-\theta) z^{\prime}\left(I-T^{d}\right)}
$$

is strictly positive by $z^{\prime}\left(I-T^{d}\left(c_{T}\right)\right) \geq z^{\prime}\left(I-T^{*}\left(c_{T}\right)\right)$ and the assumption that $\theta z^{\prime}\left(I-T^{*}\left(c_{T}\right)\right)>$ $1-\theta$. The assumption that $a^{d}$ maximizes profit, combined with $v_{a}^{d}<0$ for all $a \in\left[c_{T}, \widetilde{a}\right)$ yields $w^{d}\left(a^{d}\right)>w^{d}(a)$ for all $a \in\left(a^{d}, \widetilde{a}\right]$, and therefore $a^{o p t} \leq a^{d}$. The inequality is strict by the assumption that $a^{d}$ is an interior maximum of $\pi^{d}$.

\section{References}

Aldebert, Marc, Marc Ivaldi and Chantal Roucolle (2004): Telecommunications Demand and Pricing Structure: An Econometric Analysis, Telecommunication Systems 25, 89-115.

Armstrong, Mark (1998): Network Interconnection in Telecommunications, Economic Journal $108,545-564$.

Armstrong, Mark (2002): The Theory of Access Pricing and Interconnection, in Martin E. Cave, Sumit K. Majumdar and Ingo Vogelsang (eds.) Handbook of Telecommunications Economics 
Vol. 1, Amsterdam: Elsevier, 295-384.

Armstrong, Mark and Julian Wright (2009): Mobile Call Termination, Economic Journal 119, F270-F307.

Berger, Ulrich (2005): Bill-and-Keep vs. Cost-Based Access Pricing Revisited, Economics Letters $86,107-112$.

Calzada, Joan and Tommaso M. Valletti (2008): Network Competition and Entry Deterrence, Economic Journal 118, 1223-1244.

Carter, Michael and Julian Wright (2003): Asymmetric Network Interconnection, Review of Industrial Organization 22, 27-46.

Danaher, Peter J. (2002): Optimal Pricing of New Subscription Services: Analysis of a Market Experiment, Marketing Science 21, 119-138.

Dessein, Wouter (2003): Network Competition in Nonlinear Pricing, RAND Journal of Economics 34, 593-611.

Dessein, Wouter (2004): Network Competition with Heterogeneous Customers and Calling Patterns, Information Economics and Policy 16, 323-345.

European Commission (2007): Electronic Communications: New Regulatory Framework Principles, Fact Sheet 13, http://ec.europa.eu/information_society/newsroom/cf/itemlongdetail.cfm?item_id=1398, March 12, 2013.

Gabrielsen, Tommy S. and Steinar Vagstad (2008): Why is On-net Traffic Cheaper than Off-net Traffic? Access Markup as a Collusive Device, European Economic Review 52, 99-115.

Gans, Joshua S. and Stephen P. King (2001): Using 'Bill and Keep' Interconnect Arrangements to Soften Network Competition, Economics Letters 71, 413-420.

Genakos, Christos and Tommaso Valletti (2011): Testing the "Waterbed" Effect in Mobile Telephony, Journal of the European Economic Association 9, 1114-11142.

Grajek, Michał and Tobias Kretschmer (2009): Usage and Diffusion of Cellular Telephony, 19982004, International Journal of Industrial Organization 27, 238-249.

Hahn, Jong-Hee (2004): Network Competition and Interconnection with Heterogenous Subscribers, International Journal of Industrial Organization 22, 611-631.

Hoernig, Steffen, Roman Inderst and Tommaso Valletti (2013): Calling Clubs: Network Competition with Non-Uniform Calling Patterns, RAND Journal of Economics, forthcoming. 
Hoernig, Steffen (2012): Why Mobile Networks Prefer High Termination Rates: An Exploration of Strategic Delegation, manuscript, Nova School of Business and Economics.

Hurkens, Sjaak and Ángel L. López (2010): Mobile Termination and Consumer Expectations under the Receiver-Pays Regime, NET Institute WP \#10-12.

Hurkens, Sjaak and Ángel L. López (2013): Mobile Termination, Network Externalities, and Consumer Expectations, Economic Journal, forthcoming.

Jeon, Doh-Shin, Jean-Jacques Laffont and Jean Tirole (2004): On the "Receiver-Pays" Principle, RAND Journal of Economics 35, 85-110.

Jullien, Bruno, Patrick Rey and Wilfried Sand-Zantman (2013): Termination Fees Revisited, International Journal of Industrial Organization, forthcoming.

Karacuka, Mehmet, Justus Haucap and Ulrich Heimeshoff (2011): Competition in Turkish Mobile Telecommunications Markets: Price Elasticities and Network Substitution, Telecommunications Policy 35, 202-210.

Laffont, Jean-Jacques, Patrick Rey and Jean Tirole (1998a): Network Competition: Overview and Nondiscriminatory Pricing, RAND Journal of Economics 29, 1-37.

Laffont, Jean-Jacques, Patrick Rey and Jean Tirole (1998b): Network Competition: Price Discrimination, RAND Journal of Economics 29, 38-56.

López, Ángel L. and Patrick Rey (2012): Foreclosing Competition through Access Charges and Price Discrimination, manuscript, University of Navarra.

OECD (2011): OECD Communications Outlook 2011, OECD Publishing.

PTS (2012): Svensk Telemarknad 2011, PTS-ER-2012:17.

Röller, Lars-Hendrik and Leonard Waverman (2001): Telecommunications Infrastructure and Economic Development: A Simultaneous Approach, American Economic Review 91, 909-923.

Tangerås, Thomas (2014): Network Competition with Income Effects: Mathematical Appendix, available at www.ifn.se/thomast.

Valletti, Tommaso M. and Carlo Cambini (2005): Investments and Network Competition, RAND Journal of Economics 36, 446-467.

Vogelsang, Ingo (2003): Price Regulation of Access to Telecommunications Networks, Journal of Economic Literature 41, 830-862. 
Weyl, E. Glen and Michael Fabinger (2013): Pass-Through as an Economic Tool: Principles of Incidence under Imperfect Competition, Journal of Political Economy 121, 528-583. 